\title{
Application of the response surface methodology for the evaluation of Staphylococcus aureus inhibition with $\mathrm{Ag} / \mathrm{TiO}_{2}$ nanoparticles
}

\section{M.A. Olivares-Ramírez}

Instituto Tecnológico de Orizaba

Leticia López-Zamora ( $\sim$ llopezz@orizaba.tecnm.mx)

Instituto Tecnológico de Orizaba: Instituto Tecnologico de Orizaba https://orcid.org/0000-0003-32369462

\section{M.J. Peña-Juárez}

Autonomous University of San Luis Potosi: Universidad Autonoma de San Luis Potosi

\section{E.J. Gutiérrez-Castañeda}

UASLP: Universidad Autonoma de San Luis Potosi

\section{J.A. Gonzalez-Calderon}

Instituto Tecnológico de Celaya

\section{Research Article}

Keywords: TiO2-Ag, poly(lactic acid), antibacterial, nanoparticles, nanocomposites

Posted Date: August 10th, 2021

DOI: https://doi.org/10.21203/rs.3.rs-617251/v1

License: (c) (1) This work is licensed under a Creative Commons Attribution 4.0 International License. Read Full License

Version of Record: A version of this preprint was published at Polymer Bulletin on July 8th, 2021. See the published version at https://doi.org/10.1007/s00289-021-03822-7. 


\section{Abstract}

The present work shows the implementation of the Response Surface Methodology (RSM), fed by an experimental Central Composite Design (CCD) to find the conditions that allow maximizing the inhibition of the microorganism Staphylococcus aureus with nanoparticles of $\mathrm{TiO}_{2}$ silanized with 3Aminopropyltriethoxysilane (APTES) and doped with Ag. In addition, Poly(lactic) acid composites were prepared with these $\mathrm{Ag} / \mathrm{TiO}_{2}$ nanoparticles with the aim to confer their antimicrobial effect. The independent variables considered were $\mathrm{pH}, \mathrm{AgNO}_{3} / \mathrm{TiO}_{2}$ ratio (\% $\left.\mathrm{w} / \mathrm{w}\right)$, and $\mathrm{TiO}_{2}$ nanoparticles concentration $(\mathrm{g} / 250 \mathrm{~mL})$, and as the variable of response, the length of the diameter of the halo or zone of inhibition presented by the microorganism $(\mathrm{mm})$. Statistical analysis found that maximization of $S$. aureus inhibition occurs at intermediate levels with a value of 10 for $\mathrm{pH}$ and $5 \mathrm{~g}$ of $\mathrm{TiO}_{2}$ solids, while for the concentration of $\mathrm{AgNO}_{3}$ high levels are required, greater than $10 \% \mathrm{w} / \mathrm{w}$. Likewise, the statistical significance was determined using the Student's t-test and the p-value; it was found that the significant effect corresponds to the concentration of $\mathrm{AgNO}_{3}$, so a second experimental CCD design equirradial with two factors was considered, estimating $\mathrm{AgNO}_{3}$ concentration and $\mathrm{TiO}_{2}$ amount, the $\mathrm{pH}$ at constant 10 value. The second experimental design indicated that maximization in $S$. aureus inhibition occurs at an $\mathrm{AgNO}_{3}$ concentration between $20-25 \% \mathrm{w} / \mathrm{w}$ with high amounts of $\mathrm{TiO}_{2}$ solids $(7-8 \mathrm{~g})$, with a resulting zone of inhibition between $26-28 \mathrm{~mm}$. The quadratic model obtained, which represents the relationship between the length of the zone of inhibition with the variables considered, shows an adjustment of experimental data with a coefficient of determination $\left(R^{2}\right)$ of 0.82 .

\section{Introduction}

In recent years, the overuse of synthetic polymers has generated one of the significant environmental problems; consequently, research in the development of materials using natural polymers has responded to a global need, seeking an ecological alternative to reduce environmental impact, whose properties being biodegradable and antimicrobial, contribute to mitigating the amount of waste and environmental pollution [1-4]. Furthermore, with the growing consumer demand and concerns about the environment and limited natural resources, renewable resources to produce edible or biodegradable packaging materials that maintain product quality and safety while reducing waste are widely explored. Consequently, a variety of renewable polymers such as polysaccharides (starch and chitosan), proteins, lipids, and their compounds, as well as Polylactic Acid (PLA) and Polydimethylsiloxane (PDMS) are being developed.

The biocide properties of metal nanoparticles (MNPs) have generated significant interest for their application as new antimicrobial agents [5-6]. Nanogold has presented an excellent antibacterial efficacy towards different pathogenic bacterial species (gram-positive and gram-negative) [7-8]. The antimicrobial activity of Ag-nanoparticles was investigated against yeast, Escherichia coli, and Staphylococcus aureus, making them applicable to various medical devices and antimicrobial control systems [9-10]. Ag-Au bimetallic nanocomposite is another strategy to study the antipathogenic effect [11-12]. Carbon quantum 
dots (CQDs) and ZnO/CQDs Ncs, have recently been investigated and considered in the family of carbon nanostructures that exhibited excellent antimicrobial potency against Bacillus cereus, E. coli, S. Aureus, $S$. Typhi, and Candida albicans [13-15].

Titanium dioxide $\left(\mathrm{TiO}_{2}\right)$ is a mineral that finds naturally in three crystalline phases: anatase and rutile (both tetragonal) and brookite (rhombohedral) [4]; it is not toxic and is applied in environmental treatments such as air and water purification, disinfection, and sterilization of water due to its properties and chemical stability [16-17]. It is one of the most studied semiconductors and is an innocuous material with high resistance to photo corrosion. It is stable in aqueous solutions. It is not expensive, abounds in nature, and has good photocatalytic activity under ultraviolet irradiation [16-30]. Different routes can synthesize $\mathrm{TiO}_{2}$; these include flame synthesis, chemical vapor deposition, precipitation, and the alkoxide sol-gel method [12]. In recent years, interest in $\mathrm{TiO}_{2}$-based nanomaterials has been steadily growing because of their unique physicochemical properties. They are used for photocatalysis, solar energy engineering, air and water purification of organic pollutants, removal of heavy metal ions, detoxification of solutions, antibacterial agents, and medical devices and medicine since it is compatible with human tissues [22,31-34].

$\mathrm{TiO}_{2}$ has been used for the inhibition of microorganisms, especially Gram-positive ones such as $S$. aureus. However, there are limitations with the practical use of $\mathrm{TiO}_{2}$, since this material is only photoactive under ultraviolet irradiation $(\lambda<380 \mathrm{~nm})$, which restricts the use of $\mathrm{TiO}_{2}$ as an active catalyst for the light since most of the sunlight consists of invisible light and infrared radiation, and only about $5 \%$ of UV light [25, 31]. Various methods have been used to improve its absorption of visible light; these techniques include surface modification through sensitization of organic or semiconductor materials, modification of the band space creating oxygen vacancies or oxygen sub-valence through the doping with some nonmetals (like nitrogen) or metals (like silver) [20,31]. Modification of $\mathrm{TiO}_{2}$ with transition metals (including silver, platinum, ruthenium, and palladium) has been reported to decrease the recombination process by forming structures and new interfaces that improve photocatalytic efficiency $[17-18,27]$. An attractive solution is creating nanosystems with an $\mathrm{Ag}^{-\mathrm{TiO}_{2}}$ structure [33], not only because $\mathrm{TiO}_{2}$ is a material with desirable properties but also because Ag shows some unique chemical and biological detection activities compared to other noble metals.

Compared to other metal ions, silver-deposited $\mathrm{TiO}_{2}$ has a broad spectrum of antibacterial activity and is safe due to its non-toxic nature [35]; and has also received special attention for its low cost of synthesis and high availability [36]. Therefore, the antibacterial activity applications of silver and $\mathrm{TiO}_{2}$ generate great interest since they can be applied in the manufacturing of coated sanitary products, medical devices, surfaces for food preparation, air conditioning filters, among others. In addition, the deposition of Ag promotes the transformation of anatase to rutile, which is attributed to the increase in the specific surface area that causes the improvement in the photocatalytic activity and improves the separation of the electron-hole pair [30]. Furthermore, Ag nanoparticles photo catalytically deposited on individual rutile $\mathrm{TiO}_{2}$ crystals exhibit multicolor photo-chromism and dissolution in different sizes, and Ag deposition 
causes multicolor spectral changes [37]. Therefore, the study of $\mathrm{Ag}-\mathrm{TiO}_{2}$ modified has a significant practical value [38].

Silver (Ag) is the most studied biocide agent, and numerous information is available regarding its antimicrobial activity mechanism [9-10; 39], which is much higher than other metals [32]. It is active against Gram-negative bacteria (Escherichia coli and Pseudomona aeruginosa) and Gram-positive bacteria (Staphylococcus aureus and some species of the Streptococcus family) [21, 26-27]. There are also reports on the antimicrobial activity of $\mathrm{Ag}$ nanoparticles obtained specifically against Pseudomonas aeruginosa, Microbacterium foliorum, Bacillus subtilis and Rhodococcus equi [40]. Although there is great controversy about the mechanism of action, these could be summarized in three main points. The first would be explained by the gradual release of $\mathrm{Ag}$ ions that inhibit the production of adenosine triphosphate (ATP) and DNA replication, fundamental factors for cell survival. The second mechanism could be attributed to the ability of nanoparticles to generate direct damage to the cell membrane. Then, the third to the generation of reactive oxygen species that generate oxidative stress and subsequent cell death [4]. The production of Ag particles at the nanoscale results in the generation of a high surface area, which is an important property to inhibit bacterial growth [17-18]

To prepare metal oxide nanocomposites suitable for antibacterial materials, it is necessary to disperse in organic binders the nanoparticles without aggregation. Nanoparticles tend to agglomerate strongly due to the surface/particle size ratio. At the same time, the use of different coupling agents is recommended for surface modification of the nanoparticles to achieve adequate dispersion of the nanoparticles. A suitable surface modification in the nanoparticles leads to better dispersion and compatibility between them, and the formation of physical and chemical interactions with the polymer matrix guarantees a lasting chemical bond between two incompatible phases. It is crucial to have a homogeneously dispersed metal oxide [41-42].

Polylactic acid (PLA) is a new type of biodegradable material, which is made from renewable plant resources (such as sugar beets, corn, and potato starch) [45-46]. It has high thermal stability, biocompatibility, low cost, and low environmental impact, making it one of the most promising polymers in the 21 st century [47-49]. However, pure PLA films have some disadvantages, such as their null antimicrobial activity and poor mechanical properties. In order to improve the functional properties of PLA films, different investigations have been carried out involving the combination of $\mathrm{NPs}^{-} \mathrm{TiO}_{2}$ and $\mathrm{Ag}$ in PLA matrices to increase the effective inhibition of bacterial reproduction and mechanical properties [50-55, 17, 56-59]. In addition, researchers have worked to incorporate fillers in PLA matrices to broaden the applications of this polymer, which allows improving the antimicrobial properties [1]. The fillers that have been shown better microbicidal properties are silver, copper, zinc, titanium, and iron oxides $[2,3]$.

There are several works about the synthesis and use of $\mathrm{Ag} / \mathrm{TiO}_{2}$ nanoparticles as antibacterial agents $[16-17,19,21,43-44]$. However, there are still some limitations related to the adequate deposition of the metal. The suitable dispersion of the nanoparticles is sought to maximize inhibition against $S$. aureus. Process variables are critical for successfully applying the deposition process of Ag nanoparticles on the 
silanized $\mathrm{TiO}_{2}$ with APTES to improve their antibacterial properties, which will be evaluated through the response surface methodology with an experimental Central Composite Design. Finding the optimal conditions for silver deposition based on the highest inhibition is essential to exploit the use and application of nanoparticles. Therefore, what is sought with this work is to maximize the inhibition of S. aureus, considering different variables such as $\mathrm{pH}$, the precursor concentration, $\mathrm{AgNO}_{3}(\% \mathrm{w} / \mathrm{w})$, and amount of $\mathrm{TiO}_{2}$ in solution ( $\mathrm{g} / 250 \mathrm{~mL}$ ). With this, resources would be saved, and the $\mathrm{Ag} / \mathrm{TiO}{ }_{2}$ nanocomposites with outstanding antibacterial properties could be produced. This evaluation will be carried out by implementing a response surface methodology with a central compound type experimental design.

This research aimed to produce and characterize PLA-based high-performance biocomposites with $\mathrm{Ag} / \mathrm{TiO}_{2}$ particles to maximize the inhibition of the microorganism Staphylococcus aureus, using a DCC to obtain the best conditions. The effect of $\mathrm{pH}, \mathrm{AgNO}_{3} / \mathrm{TiO}_{2}$ ratio $(\% \mathrm{w} / \mathrm{w})$, and $\mathrm{TiO}_{2}$ nanoparticles concentration $(\mathrm{g} / 250 \mathrm{~mL})$ in structural and thermal properties and materials behavior against bacterial growth and biofilm development of a strain of E. Aureus was investigated. Once the best values of the variables were found, the nanoparticles obtained by this optimization were immersed in a PLA matrix to evaluate if the resulting polymer will have adequate antimicrobial capacity.

\section{Materials And Methods}

\section{Materials}

Nanoparticles (NPs) of $\mathrm{TiO}_{2}$ with a diameter of approximately $350 \mathrm{~nm}$ (R-104 DuPont, Mexico), 3Aminopropyltriethoxysilane Coupling Agent (APTES) (99\% Sigma Aldrich, Mexico), and silver nitrate $\left(\mathrm{AgNO}_{3}\right)(\mathrm{JT}$ Baker$)$.

\section{Experimental design}

A three-factor Central Composite Design (CCD) was proposed to study the process of Ag-nanoparticle deposition in $\mathrm{TiO}_{2}$ in order to determine the influence of each of these considered factors. The CCD is a fractionated factorial or factorial design with central points, enlarged with a group of axial points that allow estimating the curvature, are used to estimate the first- and second-order terms efficiently and to model a response variable with curvature by adding central and axial points to a previously executed factorial design [60]. The variables evaluated were $\mathrm{pH}\left(\mathrm{X}_{1}\right), \mathrm{AgNO}_{3} / \mathrm{TiO}_{2}$ ratio $(\% \mathrm{w} / \mathrm{w})\left(\mathrm{X}_{2}\right)$, and $\mathrm{TiO}_{2}$ nanoparticles concentration $(\mathrm{g} / 250 \mathrm{~mL})\left(\mathrm{X}_{3}\right)$ having as a response variable, the inhibition zone on the discs (halos measured in $\mathrm{mm}$ ) of each of the experimental units, in order to demonstrate that there is a significant influence of these variables on the inhibition of Staphylococcus aureus. The matrix studied for this CCD is shown in Table 1.

\section{Statistical analysis}


MINITAB 2017 Statistical Software (version 17.1; MINITAB Inc., State College, PA, USA) was used for data analysis, prediction models, and construction of surface and contour plots. The accuracy of the polynomial equations was expressed by $\mathrm{R}^{2}$ (coefficient of determination), and the F-test verified their statistical significance at a $95 \%$ confidence level.

\section{Surface modification of $\mathrm{TiO}_{2}$ nanoparticles with APTES}

Incorporating the coupling agent (APTES) superficially on the $\mathrm{TiO}_{2}$ surface is known as silanization. The best coupling route for the modification of $\mathrm{TiO}_{2}$ NPs [41] requires $1 \mathrm{~mL}$ of APTES and $100 \mathrm{~mL}$ of ethanol for every $5 \mathrm{~g}$ of $\mathrm{TiO}_{2}$ to be modified. For incorporating $\mathrm{TiO}_{2}$ in ethanol, 30 minutes of stirring were needed using a stirring magnetic grid (Thermo Scientific, Cimarec) with 30 minutes of sonication at $60 \mathrm{~Hz}$ in an ultrasonic bath (Bransonic, model 5510R-MT) until completing a total time of 2.5 hours. Subsequently, the APTES was added, and in a 10-minute interval, $1 \mathrm{~mL}$ of water was added to allow hydrolysis in the reaction. This mixture was left stirring at $400 \mathrm{rpm}$ for 6 more hours. The solution was placed in $50 \mathrm{~mL}$ falcon tubes for centrifugation and was washed twice with distilled water and five times with methanol to remove the reaction medium. Each washing was performed at $300 \mathrm{rpm}$ for 10 minutes with approximately $30 \mathrm{~mL}$ of solvent. The silanized sample was dried at $80^{\circ} \mathrm{C}$ for 3 hours. The dry material was stored in vials for subsequent characterization and use.

\section{Fourier Transform Infrared Spectroscopy (FTIR) and Thermo-gravimetric Analysis (TGA)}

The FTIR spectra of unmodified silanized $\mathrm{TiO}_{2}$ NPs were measured using a Fourier Transform Infrared spectrometer (FTIR-ATR Perkin Elmer, Spectrum 100 model). The analyses included the wavenumber range of 3000 to $1000 \mathrm{~cm}^{-1}$ with 80 scans or sweeps per spectrum, placing the NPs in granular form for a better reading [52]. The thermo-gravimetric analysis was carried out on a TGA (TA Instruments Model Q500), performed in a temperature range of 25 to $600^{\circ} \mathrm{C}$, with a heating ramp of $10^{\circ} \mathrm{C}$ per minute in a nitrogen atmosphere with a constant flow of $60 \mathrm{~mL}$ per minute. A sample of about $10 \mathrm{mg}$ was placed in platinum baskets [41].

\section{Electron Transmission Microscopy (TEM)}

The size and morphology of the NPs were obtained by transmission electron microscopy (TEM) on a 200 $\mathrm{kV}$ microscope (JEOL model JEM 1230). The samples consisted of $0.005 \mathrm{~g}$ of each nanocomposite suspended in $2 \mathrm{~mL}$ of ethanol and sonicated for $5 \mathrm{~min}$, and a drop of $10 \mu \mathrm{L}$ was placed on a copper grid [61].

\section{Z Potential}

The samples were sonicated and mixed with a Vortex-Genie 2 Scientific Industries vortex shaker To make colloidal solutions [41]. The surface charge (Zeta potential) of the two different $\mathrm{TiO}_{2}$ nanoparticle systems was characterized by a Delsa Nano C Particle Analyzer Z-Potential meter (A53878), using electrophoretic light scattering (ELS). This equipment has a dual source of $30 \mathrm{~mW}$ and a laser diode of 
$659 \mathrm{~nm}$. The method consisted of suspending the NPs in water at a concentration of $0.01 \% \mathrm{w} / \mathrm{v}$ by scanning $\mathrm{pZ}$ at different $\mathrm{pH}$ (measured in a Thermo Scientific potentiometer, model Orion Star A211) modified with $\mathrm{HCl} 0.1 \mathrm{~N}$ and $\mathrm{NaOH} 0.1 \mathrm{~N}$ [62].

\section{Nuclear magnetic resonance (NMR)}

The NMR spectra $\left({ }^{29} \mathrm{Si}\right.$ and $\left.{ }^{13} \mathrm{C}\right)$ of the NPs were obtained from the Bruker Ascend equipment $(400 \mathrm{MHz})$, which operates at $400 \mathrm{MHz}$ for ${ }^{29} \mathrm{Si}$ and $100 \mathrm{MHz}$ for ${ }^{13} \mathrm{C}$. The parameters established for the ${ }^{13} \mathrm{C}$ case were a scan number of 16 and a pulse length of $8.5 \mu \mathrm{s}$.

\section{Deposition process of $\mathrm{TiO}_{2}$ with $\mathrm{Ag}$ by reduction of $\mathrm{AgNO}_{3}$}

The preparation of metallic silver on the $\mathrm{TiO}_{2}$ surface was based on the $\mathrm{AgNO}_{3}$ chemical reduction route proposed by [44]. The amount of $\mathrm{TiO}_{2}$ (total solids), the $\mathrm{pH}$, and the $\mathrm{Ag} / \mathrm{TiO}_{2}$ ratio (\% w/w) followed the experimental design proposed in Section 2.2. The aqueous suspension of $\mathrm{TiO}_{2} \mathrm{NPs}$ was prepared by adding the required amount of it to $250 \mathrm{~mL}$ of deionized water followed by sonication for 10 minutes, heating it to $80^{\circ} \mathrm{C}$ with vigorous agitation on a magnetic grid. Once the temperature was reached, the required amount of $\mathrm{AgNO}_{3}$ was added to the suspension to obtain the desired concentration, maintaining heating and stirring. The required $\mathrm{pH}$ of the suspension was adjusted with $\mathrm{NaOH} 0.5 \mathrm{M}$, the suspension at $80^{\circ} \mathrm{C}$ was mixed for 2 hours. The solution was placed in falcon tubes for later centrifugation, performing two washes with distilled water to remove unreacted agents. Each wash was performed at $300 \mathrm{rpm}$ for 10 minutes with approximately $30 \mathrm{~mL}$ of water. The mixture obtained was dried in a convection oven (LabLine Instruments, model 3471 ) at $80^{\circ} \mathrm{C}$ for 12 hours.

\section{Antibacterial test}

The Inhibition test was performed by the disk diffusion method, a modification of the technique described by Bauer, Kirby, Sherris, and Turk; it is described in the following sections [63]. Medium. Mannitol Salt Agar was used. The medium was prepared according to the instructions on the package. Because the temperature of the medium was high at the end of the sterilization time, it was necessary to place it in a water bath until a temperature of approximately $48-50^{\circ} \mathrm{C}$ was reached. Finally, the medium was distributed in approximately $25 \mathrm{~cm}^{3}$ in Petri dishes, previously sterilized.

Filter paper discs for nanoparticle impregnation. Filter paper disks were prepared for the different experimental units. First, they were cut out with a commercial hole punch; these discs were each $6 \mathrm{~mm}$ in diameter, 6 to 8 discs were placed in number in Eppendorf tubes of $2 \mathrm{~mL}$ capacity (1 tube for each system). Once this was done, the tubes were sterilized in an autoclave at $121^{\circ} \mathrm{C}$ for $15 \mathrm{~min}$. Once labeled, approximately $1.5 \mathrm{~mL}$ of the nanoparticle solution at $1000 \mathrm{ppm}$ from each system were added to each tube; before this, the tubes remained in a UV light chamber for 15 min. Finally, they were stored at room temperature for $24 \mathrm{~h}$ to allow the nanoparticles to soak into the discs. 
Inoculum. 4 to 5 colonies of the microorganism were selected from a pure culture. The colonies were transferred by touching the top of each with a bacteriological loop to a tube containing $3-5 \mathrm{~cm}^{3}$ of sterile Mueller-Hilton broth. It was incubated at $35^{\circ} \mathrm{C}$ for 2 to $8 \mathrm{~h}$ until moderate growth occurred. This growth was determined by comparing the pure broth with the one containing microorganisms; a change in turbidity was attributed to the growth of microorganisms. The culture was diluted with sterile broth at 5: 9 until obtaining a turbidity equivalent to a 0.5 tube on the McFarland scale, which corresponds to approximately 108 viable microorganisms per $\mathrm{mL}$.

Turbidity standard. To prepare the standard, $0.5 \mathrm{~mL}$ of $\mathrm{BaCl}_{2}$ dihydrate $(1.175 \% \mathrm{w} / \mathrm{v})$ was added to 99.5 $\mathrm{mL}$ of $\mathrm{H}_{2} \mathrm{SO}_{4} 0.36 \mathrm{~N}(1 \% \mathrm{w} / \mathrm{v})$. It was mixed perfectly and distributed in screw cap tubes in a quantity of 6$8 \mathrm{~mL}$; were hermetically sealed and stored in a dark place at room temperature. To make a comparison with the culture, the standard was vortexed.

Sample seeding. The seeding of the sample was carried out in an extraction hood, previously sterilized with UV light. A sterile cotton swab was immersed into the tube with the suspension of the microorganism in turn, in a 5: 9 dilution (this dilution does not exceed the standard turbidity equivalent to 0.5 on the McFarland scale). Once the swab was inside, it was placed above the level of the contents of the tube and rotated against the tube walls to remove excess inoculum. The inoculum was then evenly seeded on the medium surface of the Petri dish with the swab. This seeding was carried out in four directions, rotating the Petri dish 90 degrees. Thus, it was avoided that the inocula were very concentrated or diluted and that parts of the medium remained uninoculated. Once the boxes of all the systems were inoculated, it was necessary to allow the surface of the seeded medium to dry for 15 minutes, keeping the Petri dish closed. After a lapse of time, the Eppendorf tubes were labeled with each system (which rested for twenty-four hours to impregnate the nanoparticles), discs were placed on the surface of the agar with sterile forceps. The discs were slightly pressed on the agar to ensure uniform contact. Each box corresponding to each Eppendorf tube of each system was labeled. A total of 3 discs were placed on the surface of the medium, trying to leave a uniform space between each disc to observe the results of the inhibition halos better. Once the Petri dishes already contained the discs on the surface, they were wrapped with parafilm paper to avoid sudden movements of the medium. Finally, in a drying oven (LabLine Instruments, model 3471 ), all the boxes were incubated at $35^{\circ} \mathrm{C}$ for $36 \mathrm{~h}$ to allow the microorganism to grow.

\section{Measurement of inhibition halos}

To measure the zone of inhibition of each disk, the samples were kept inside the extraction hood on the dark surface, with good lighting and lights reflected on the boxes. Next, electronic photos with 12MP resolution were taken of each of the systems. Finally, these stored photos were analyzed with ImageJ version 1.52a software to obtain the average diameter of the experimental units.

\section{Characterization of $\mathrm{TiO}_{2}$ particles deposited with $\mathrm{Ag}$}


The characterization of $\mathrm{TiO}_{2}$ particles deposited with $\mathrm{Ag}$ was performed within the experimental units that presented the highest and lowest halo/zone inhibition. The samples were analyzed by transmission electron microscopy (TEM) to confirm the superficial modification and the Ag-deposition, using a JEOL equipment (model JEM 1230 microscope) with a resolution of $0.4 \mathrm{~nm}$ and an acceleration voltage of 100 kV.

\section{Preparation of PLA composites with Ag-deposited $\mathrm{TiO}_{2}$ nanoparticles}

PLA composites at $0.1 \% \mathrm{w} / \mathrm{w}$ were prepared. First, $500 \mathrm{mg}$ of PLA were dissolved in $20 \mathrm{~mL}$ of chloroform; once a homogeneous solution was obtained, $0.5 \mathrm{mg}$ of NPs were added and then stirred and sonicated for $30 \mathrm{~min}$ at $60 \mathrm{~Hz}$ in an ultrasonic bath. Finally, the suspension obtained was placed on a glass container (silica), and the solvent was evaporated at room temperature. This procedure was made for each system of nanoparticles.

\section{Antibacterial analysis of PLA films by drop-test method}

PLA composites were tested against $S$. aureus using the antibacterial drop-test method with some modifications [4]. First, a film of each respective composite was introduced in a different test tube, in duplicate, each containing nutrient broth inoculated with the bacteria. Moreover, a culture of the microorganism was grown without any treatment as a control. Then the tubes were incubated for $24 \mathrm{~h}$, and the solutions were read with a spectrophotometer. The optical absorptions [A] were recorded, and the inhibition rate (\%) was calculated according to the following equation:

$$
\text { Inhibition rate }(\%)=\frac{[A]_{i}-[A]_{c}}{[A]_{i}} \times 100
$$

where $[A]_{i}$ is the optical absorption of control bacteria, and $[A]_{c}$ is the absorption of each composite.

\section{Characterization of the $\mathrm{TiO}_{2}$ nanoparticles and PLA composites by X-ray diffraction (XRD)}

The XRD-measurements for the $\mathrm{TiO}_{2}$ nanoparticles and PLA composites were used to investigate the crystalline structure of the pristine and $\mathrm{Ag}$-deposited $\mathrm{TiO}_{2}$ and the influence of these nanoparticles in the crystalline structure of the PLA composites by using a Bruker Model D8 ADVANCE diffractometer with Lynx Eye detector and Copper tube (Wavelength 1.5406A). The scanning of samples (2q) was performed at $20-80^{\circ}$ with a $0.02^{\circ}$ increment.

\section{Results And Discussion}

\section{Experimental design and response surface methodology}

The application of the experimental CCD design and the response surface methodology allowed the researchers to know the conditions that had a better inhibition of Staphylococcus aureus by using nanoparticles of $\mathrm{TiO}_{2}$ modified and deposited with $\mathrm{Ag}$ as an antibacterial agent. The zone of inhibition, 
the halos present in the $S$. aureus plate $(\mathrm{mm})$, obtained by CCD design established are shown in Table 2 . The sizes of the halos are in a range of 7.32 to $11.26 \mathrm{~mm}$.

The application of the RSM generated the second-order regression polynomial (Eq.1), which represents an empirical relationship between the response (length of the inhibition halos with Staphylococcus aureus) and the evaluated variables. The statistical significance of each of the coefficients was evaluated by the Student's t-test and the p-value. Table 3 shows the variables and interactions that have the highest incidence on the deposition process in Staphylococcus aureus inhibition. In Table 3, a significant variable is found when the p-value is less than 0.05 , which indicates that the effect is significant with $95 \%$ confidence. Therefore, the significant effect corresponds to AgNO3 (x2) concentration, while the $\mathrm{TiO}_{2}$ solids in solution and $\mathrm{pH}$ are not significant in the process, being $\mathrm{pH}$ the least influential. The model shows a good fit with the experimental data, having a coefficient of determination $\left(R^{2}\right)$ of 0.86 , implying that $86.00 \%$ of the variables fit the model and that it only does not explain $14 \%$ of the total variation.

$$
\begin{gathered}
y=-13.45+4.468 x_{1}-0.818 x_{2}+1.472 x_{3}-0.2347 x_{1}^{2}+0.0018 x_{2}^{2}-0.1479 x_{3}^{2}+ \\
0.0636 x_{1} x_{2}-0.0434 x_{1} x_{3}+0.0650 x_{2} x_{3}
\end{gathered}
$$

The analysis of the response surface, illustrated in Fig. 1, shows the behavior of the different combinations of effects on the size of $S$. aureus inhibition halos, in which the largest size occurs at intermediate levels, $\mathrm{pH}$ of 10 and $5 \mathrm{~g}$ of $\mathrm{TiO}_{2}$ solids in solution. In contrast, for $\mathrm{AgNO}_{3}$ concentration, high levels are required $(10 \% \mathrm{w} / \mathrm{w})$. The most suitable working ranges were determined from the contour graph, Fig. 2; the results obtained were $\mathrm{pH} 9$ to 11, a $\mathrm{TiO}_{2}$ amount between 4 and $6 \mathrm{~g}$, while the range of $\mathrm{AgNO}_{3}$ concentration covers a region above $11 \% \mathrm{w} / \mathrm{w}$. From the second-order model (Eq. 1), the canonical model (Eq. 2) was obtained, and the characteristic values, with alternating signs $\left(\lambda_{1}=-0.2459, \lambda_{2}=\right.$ $\left.-0.1464, \lambda_{3}=0.0115\right)$, determine that the results show a saddle point.

$$
\hat{y}=9.7357-0.2459 w_{1}^{2}-0.1464 w_{2}^{2}+0.0115 w_{3}^{2}
$$

Based on the results obtained, a second equi-radial experimental CCD design was established with two factors (Design 2), considering as independent variables: $\mathrm{AgNO}_{3}$ concentration concerning $\mathrm{TiO}_{2}\left(\mathrm{X}_{1}\right)(25$, 35 , and $45 \% \mathrm{w} / \mathrm{w})$ and the amount of $\mathrm{NPs}$ of $\mathrm{TiO}_{2}$ in solution $\left(\mathrm{X}_{2}\right)(3,5$ and $7 \mathrm{~g} / 250 \mathrm{~mL})$, and now with constant $\mathrm{pH}$ in 10. The response variable remains the same, size of the halo or zone of inhibition of the disks (diameter of halos in $\mathrm{mm}$ ). Table 4 shows the results obtained from Design 2 of the disk test. The ranges of the $S$. aureus halo of this second proposed design are between 13.16 and $22.09 \mathrm{~mm}$, and compared to the first experimental design (7.32 to $11.26 \mathrm{~mm}$ ), it presents an increase of $96.18 \%$, which indicates that there is an enhancement of almost the double in halo size.

Statistical analysis of the results using the Student's t-test and calculation of the p-value provided the estimated coefficients for the quadratic model. Table 5 shows the variables and interactions present in the deposition process in Staphylococcus aureus inhibition. As a result of Design 2, the p-value shows 
that the $\mathrm{TiO}_{2}$ solids in solution remain as a non-significant variable, while the $\mathrm{AgNO}_{3}$ concentration is the significant variable in the deposition process due to the $\mathrm{p}$-value was found below 0.05 .

The response function (length of the inhibition halos with Staphylococcus aureus) was represented using an RSM through a second-degree polynomial equation (Eq. 3), where the two independent variables were considered. As a result, the quadratic model shows an acceptable fit of experimental data, with a coefficient of determination $\left(\mathrm{R}^{2}\right)$ of 0.82 , which implies that $82.00 \%$ of the experimental data fit the model; therefore, $18 \%$ of the total variation was unexplainable.

$y=14.9-0.370 x_{1}+1.07 x_{2}+0.01678 x_{1}^{2}+0.343 x_{2}^{2}-0.1253 x_{1} x_{2}$

In the response surface graph, Fig. 3 , it was observed that the maximization of $S$. aureus inhibition occurs at a low concentration of $\mathrm{AgNO}_{3}(20-25 \% \mathrm{w} / \mathrm{w})$ with high amounts of $\mathrm{TiO}_{2}$ solids. (7-8 g), observing the highest levels of inhibition (26-28 mm) highlights the importance of the addition of $\mathrm{TiO}_{2}$ solids. In the statistical analysis, the $\mathrm{X}_{1} \mathrm{X}_{2}$ interaction was significant; this was observed in the curvature shown by the surface graph. The significance of this interaction indicates that within the experimental domain, synergistic interaction effects commonly attributed to the dispersion of $\mathrm{TiO}_{2}$ particles were observed when they are dispersed in an aqueous medium in the Ag deposition process.

The most suitable working ranges were determined through the contour graph, Fig. 4, having a value between 21 and $24 \% \mathrm{w} / \mathrm{w}$ for the $\mathrm{AgNO}_{3}$ concentration, with a $\mathrm{TiO}_{2}$ quantity ranging from 7.5 to $7.8 \mathrm{~g}$. The results obtained from the second experimental design allowed determining that an $\mathrm{AgNO}_{3}$ concentration between $20-25 \% \mathrm{w} / \mathrm{w}$ with amounts of silanized $\mathrm{TiO}_{2}$ between 7-8 $\mathrm{g}$ and $\mathrm{pH}$ of 10 achieves an inhibition zone of $28 \mathrm{~mm}$ in Staphylococcus aureus. This value has improved $300 \%$ regarding the zone of inhibition, reported by [64], who analyzed the antibacterial behavior of an $\mathrm{Ag} / \mathrm{TiO}_{2} / \mathrm{PVC}$ composite membrane tested in the same bacterial strain. Likewise, an increase of just over $200 \%$ was found in the inhibition of the same microorganism, given that they tested $\mathrm{Ag}$ and $\mathrm{TiO}_{2}$ modified polycaprolactone nanofibers $\left(\mathrm{PCL} / \mathrm{TiO}_{2}-\mathrm{Ag}\right.$ ), showing an antibacterial impact of $9.2 \mathrm{~mm}$ in the diameter of the zone of inhibition [66]. In other research [36], a $40 \%$ increase in the zone of inhibition was obtained compared to unmodified $\mathrm{Ag} / \mathrm{TiO}_{2}$ nanoparticles since they showed a maximum zone of inhibition of $20 \mathrm{~mm}$ when working with a similar strain of $S$. aureus (methicillin-resistant).

The most surprising results emerging from the data are that these $\mathrm{Ag} / \mathrm{TiO}$, showed excellent inhibition against $\mathrm{S}$. aureus since inhibition is better than previous reports. For example, Emam et al. [7] found no antibacterial activity against this gram-positive bacterium using AuNPs obtained sing starch polymer. While Ahmed et al. [12] obtained nanoparticles using hydroxyethyl cellulose as nanogenerator and surfactant, they reported an inhibition zone of only $16 \mathrm{~mm}$ using AgNPs obtained, $15 \mathrm{~mm}$ with AuNPs, and $18 \mathrm{~mm}$ with $\mathrm{Ag}$-Au bimetallic nano-alloy.

\section{Characterization of $\mathrm{TiO}_{2}$ nanoparticles}


Surface-modified $\mathrm{TiO}_{2}$ nanoparticles were used in the Ag deposition process and subsequently used in the antibacterial test. The modification of the surface of $\mathrm{TiO}_{2}$ was carried out with APTES; these particles underwent a series of tests to confirm the presence of silica (present in APTES) on the oxide surface. One of the characterizations performed was the FTIR, which provides information about the functional groups present in the samples to be analyzed. Fig. 5 shows the results of the FTIR spectra for unmodified (black line) and modified $\mathrm{TiO}_{2}$ (red line). It is essential to mention that new bands appeared in the particles modified with APTES; symmetric and asymmetric stretching vibration of the $\mathrm{C}-\mathrm{H}$ bond was observed in the methylene group at 2960, 2927, and $2858 \mathrm{~cm}^{-1}[29,66-67]$.

The peak spanning between 1630 to $1640 \mathrm{~cm}^{-1}$ is attributed to the stretching vibration of absorbed water and the hydroxyl $(\mathrm{OH}-)$ groups present on the surface of the nanoparticles $[29,66,52,68]$. The small peak at $1641 \mathrm{~cm}^{-1}$ corresponds to the stretching vibration of the $(\mathrm{NH}) \mathrm{C}=0$ group [66]. Other evidence of the modification with APTES on the nanoparticle surface is the peak at $1560 \mathrm{~cm}^{-1}$ that corresponds to the flexion of the amino-functional group $\left(-\mathrm{NH}_{2}\right)[66,68]$. The peak shown between 1420 and $1490 \mathrm{~cm}^{-1}$ corresponds to the elastic band of the $\mathrm{C}-\mathrm{H}$ organic group bond $[29,32,52]$. The peak observed at 1378 $\mathrm{cm}^{-1}$ was assigned to the $\mathrm{C}-\mathrm{N}$ aromatic amine group [65]. The stretch band of the $\mathrm{C}-\mathrm{O}$ group bonds is also observed at $1259 \mathrm{~cm}^{-1}$ [62] and the carbonyl group at $1300 \mathrm{~cm}^{-1}$ [52]. Finally, the last peaks around 1120 , 1130 , and $1044 \mathrm{~cm}^{-1}$ are attributed to the Si-O-Si bond, indicating polymeric siloxane as a product of the organosilane precursor $[29,66,52,68]$. Similarly, peaks at 1045,1075 , and $1130 \mathrm{~cm}^{-1}$ are attributed to Ti$0-\mathrm{C}$ bonds $[29,66,52]$. The superficial modification of the $\mathrm{TiO}_{2}$ nanoparticles with the coupling agent (APTES) is confirmed with the above described.

On the other hand, to analyze size and morphology, transmission electron microscopy is a suitable test for this purpose. The images provided by TEM gave further evidence of the superficial modification of the $\mathrm{TiO}_{2}$ NPs with the coupling agent APTES. Fig. 6 (a) shows $\mathrm{TiO}_{2}$ without modification. These NPs do not have a uniform surface, and it is appreciated how they tend to agglomerate. This behavior is due to the surface/particle size ratio that causes strong agglomerates that limit its suspension stability. Besides, this is attributed to Van der Waals forces, and the attracting effect tends to decrease the dispersion of the nanoparticles. While in Fig. 6 (b), the micrograph is observed after performing the silanization process. It is possible to observe an organic coating due to the APTES bound to the $\mathrm{TiO}_{2}$ surface with an average of $2.82 \mathrm{~nm}$ thick. All this information confirms the presence of the coupling agent on the $\mathrm{TiO}_{2}$ surface.

However, it was necessary to verify that the superficial modification of the $\mathrm{TiO}_{2}$ led to an improvement in the dispersion and colloidal stability, which is necessary to facilitate the interaction in the aqueous medium of these nanoparticles in the deposition process with $\mathrm{Ag}$. The profiles of $\mathrm{Z}$ potential as a function of the $\mathrm{pH}$ of pure $\mathrm{TiO}_{2}$ (unmodified) and silanized $\mathrm{TiO}_{2}$ (modified) are observed in Fig. 7. After surface modification of the NPs, the Zeta potential of the silanized $\mathrm{TiO}_{2} \mathrm{NPs}$ increased considerably due to the amino groups $\left(\mathrm{NH}_{2}\right)$ that appeared in the outer layer of the surface of the NPs. 
The increase in the positive charge generated by the protonation of the amino groups caused an increase in the positive Zeta potential in the acid region [67], increasing the repulsion between the NPs. Likewise, this increase in the $Z$ potential is favorable because it prevents instability (IEP) and agglomeration [41]. The IEP value for the unmodified oxide is approximately at $\mathrm{pH} 3.5$, lower than for modified $\mathrm{TiO}_{2}$, at $\mathrm{pH}$ 5.6. This shift in IEP is attributed to the alkaline characteristics of $\mathrm{NH}_{2}$ groups [52] or the easy desorption of hydrogen $\left(\mathrm{H}^{+}\right)$protons found on the NPs surface of silanized $\mathrm{TiO}_{2}$. All the aforementioned indicates that the surface behavior of the $\mathrm{TiO}_{2} \mathrm{NPs}$ changed very markedly and that at the same time, the dispersion of the nanoparticles favors the deposition process with $\mathrm{Ag}$ since there is a higher surface ratio of $\mathrm{TiO}_{2}$ nanoparticles dispersed that come into contact and interact with the metal favoring the process and the amount of silver deposited on the surface. Values of $Z$ potential from - 30 to $30 \mathrm{mV}$ indicate instability in the system; values below -30 and above $30 \mathrm{mV}$ indicate an increase in stability, increasing with higher absolute values of the $Z$ potential [41].

Another essential characteristic sought when developing these types of materials is that they acquire the ability to withstand high temperatures and that there is no degradation thereof, to such a degree that the material is not lost: at the same time, it maintains its characteristics and properties. The TGA analysis corresponding to unmodified $\mathrm{TiO}_{2}$ is shown in Fig. 8 (black line), in which it is possible to observe that it remains practically stable from $25^{\circ} \mathrm{C}$ to $800{ }^{\circ} \mathrm{C}$, unlike the functionalized system present losses of weight. When analyzing the thermal degradation of the coupling agent APTES on the surface of the $\mathrm{TiO}_{2}$, Fig. 8 (blue line), it can be distinguished that the modified material has thermal stability at high temperatures, such as the temperatures used in industrial polymer processes, for example, since at approximately $98.5^{\circ} \mathrm{C}$ only $0.15 \%$ by weight of the material is lost, at $563^{\circ} \mathrm{C}$ a total of $0.38 \%$ is lost. Finally, until $734^{\circ} \mathrm{C}$, a total of $0.56 \%$ of material is lost in weight. This result is incredibly low since little more than $99.4 \%$ of the total is conserved; the loss in weight is related to the decomposition of the organic chains of the coating with APTES.

The characterization of the NMR spectrum for ${ }^{13} \mathrm{C}$, Fig. 9, shows the existence of 3 peaks in the spectrum that correspond to signals $12.40,27.84$, and 45.76 ppm, they are identified in Fig. 9 as $C_{1}, C_{2}$, and $C_{3}$, these signals refer to the three carbons of the propyl group (a group that is present in the coupling agent APTES), these signals are approximately the same indicating that the carbons are in the same amount on the surface of the $\mathrm{TiO}_{2}$. As already mentioned, the signals belong to carbons. However, the difference between each one is related to the type of group to which it is bond, Carbon 1 is the one that is bond to Silicon, Carbon 2 is linked to two other carbons, and Carbon 3 would be the one that is linked to the amino group $\left(\mathrm{NH}_{2}\right)$. On the other hand, in Fig. 10, the NMR spectrum for ${ }^{29}$ Si denotes signals at -67.43 and -59.45 ppm, identified as $\mathrm{T}_{3}$ and $\mathrm{T}_{2}$, respectively, attributed to the silica found on the surface of $\mathrm{TiO}_{2}$. $\mathrm{T}_{3}$ is assigned to the bond between silica in the APTES and three oxygens on the $\mathrm{TiO}_{2}$ surface. In comparison, $\mathrm{T}_{2}$ silicon refers to silica bonds with only two oxygens on the $\mathrm{TiO}_{2}$ surface and one remaining oxygen as hydroxyl $(\mathrm{OH})$ group. 
Characterization of $\mathrm{TiO}_{2}$ particles deposited with $\mathrm{Ag}$ considering the highest and the lowest result of the response variable of the two-factor experimental CCD design.

The results obtained from implementing the experimental design on the microorganism inhibition allowed the researchers to know the highest and lowest size of the inhibition zone. The results of Table 4 made it possible to determine that the experimental unit 6 presented the maximum size of inhibition $(22.09 \mathrm{~mm})$. While sample 1 determined that the halo size $(13.16 \mathrm{~mm})$ was not favored under these conditions. Nevertheless, the inhibition of the microorganism exists in all the experimental units of the CDC. Therefore, the characterization was carried out using TEM/EDS to explain the behavior of these two samples.

Fig. 11 illustrates the TEM micrograph of experimental unit 6 of Table 4. This sample was made up of $49.14 \% \mathrm{w} / \mathrm{w} \mathrm{AgNO}_{3}$ concentration and $5 \mathrm{~g}$ of $\mathrm{TiO}_{2}$, that is, the points $(+1.4142,0)$ of the CCD of two-factor, founding the maximum length of inhibition for $S$. aureus $(22.09 \mathrm{~mm})$. On the other hand, Fig. 12 shows the micrograph of experimental unit 1, which obtained the shortest length of the microorganism's inhibition halo $(13.16 \mathrm{~mm})$. This sample was prepared with $25 \% \mathrm{w} / \mathrm{w} \mathrm{AgNO}_{3}$ concentration and $3 \mathrm{~g}$ of $\mathrm{TiO}_{2}$, that is, the axial points $(-1,-1)$ of the two-factor CCD. Morphologically in both experimental units, $\mathrm{TiO}_{2}$ nanoparticle with Ag dots on the surface can be seen; the difference is distinguished in the amount of $\mathrm{Ag}$ that is superficially distributed on the $\mathrm{TiO}_{2}$ nanoparticle. This difference is mainly attributed to the $\mathrm{AgNO}_{3}$ concentration that was used in each sample.

The chemical analysis provided by TEM-EDS of the Ag-deposited $\mathrm{TiO}_{2}$ is shown in Fig. 13 and Fig. 14 of the experimental units 6 and 1, respectively. From this analysis, the chemical composition of each sample was obtained. The results of this analysis confirmed the presence of silver (b), oxygen (c), and titanium (d), which interact during the deposition process with the metal. Furthermore, it is possible to observe that $\mathrm{Ag}$ is distributed on the surface of $\mathrm{TiO}_{2}$ (same that is confirmed in Fig. 11 and Fig. 12), this indicates a correct dispersion of $\mathrm{AgNO}_{3}$ during the deposition process with the oxide because an ideal chemical interaction was assumed by improving the dispersion of $\mathrm{TiO}_{2}$ after the silanization process with APTES. The different compositions of the samples are found in Table 6.

The results of the drop-test method carried out to the composites against $S$. aureus are shown in Fig. 15. The values indicate inhibition activity in the PLA composites prepared with $0.1 \% \mathrm{TiO}_{2}$ nanoparticles deposited with Ag. As observed, better inhibition was obtained for the system with the highest result of the response variable of the two-factor experimental CCD design, M6, with an $18.75 \%$ of inhibition rate. Nevertheless, the lowest result, M1, also presented inhibition activity but with less efficiency, only $6.25 \%$. Therefore, with this information, it is possible to report that it is possible to confer the antimicrobial property from the $\mathrm{TiO}_{2}$ deposited with $\mathrm{Ag}$ to the PLA composites [1]. Last, with this antibacterial test was possible to corroborate the applicability of the experimental CCD design since the best inhibition result for the composite (PLA-M6) aggress with the highest value obtained for the $\mathrm{TiO}_{2}$ deposited nanoparticles in the disc diffusion method. 
Compared with the literature, although these results may look lower values than those reported previously, it is important to mention that the filler $\left(\mathrm{Ag} / \mathrm{TiO}_{2}\right)$ in the PLA matrix is exceptionally low. For example, Emam [11] reported a high reduction percentage in S. aureus (96-100); nevertheless, he stated that the antibacterial efficacy was attributed to the bi-action of two nanoparticles: silver and gold; in addition, they worked with a high amount of nanoparticles $(0.5 \mathrm{~mL} / 20 \mathrm{~mL})$. At the same time, Ahmed et al. [12] reported great inhibition rates against $S$. aureus of approximately $60 \%$, but with approximately $0.3 \%$ of Au content in silk fabrics. With all this information, it is possible to state that the composites prepared at $0.1 \%$ of $\mathrm{Ag} / \mathrm{TiO}_{2}$ in PLA are consistent and even better than previous reports regarding the nanoparticle content.

XRD-patters were used to know the crystalline structure of the $\mathrm{TiO}_{2}$ particles deposited with Ag. Fig. $15 \mathrm{~A}$ shows by X-ray diffraction (XRD) the results, and it can be observed the characteristic peaks for the structures of anatase and rutile in both samples; these results are due to both phases of titanium dioxide are mixed during their industrial origin [5]. Besides, it is possible to observe the characteristic peaks of the silver nanoparticles at $32.12^{\circ}(101)$ and $38.01^{\circ}$ (111) [5]. While Fig. 15B shows the structures of the PLA nanocomposite films were analyzed to study the effect of nanoparticle content on the crystallinity of the PLA matrix. Both XRD patterns showed an amorphous curve indicating a low degree of crystallinity of PLA and a maximum intensity at approximately $2 \theta=17^{\circ}$ attributed to the characteristic peaks of PLA [6] [7]. On the other hand, the absence of $\mathrm{TiO}_{2}$ peaks or new diffraction peaks can be seen, which can be attributed to the few numbers of functionalized nanoparticles (only $0.1 \%$ ) immersed in the PLA matrix. This information suggests that the structure of PLA was not changed by incorporating the $\mathrm{TiO}_{2}$ particles deposited with Ag [8].

\section{Conclusions}

The superficial modification of the $\mathrm{TiO}_{2}$ nanoparticles with APTES has a significant influence because they tend to agglomerate due to their high surface area to volume ratio. A correct superficial modification of the $\mathrm{TiO}_{2}$ nanoparticles was achieved, which was demonstrated with the dispersion of the silanized material favoring colloidal stability; since electrostatic charges increased the repulsion between the nanoparticles present, the measurement of $Z$ Potential gave a value that is outside the range of instability. Likewise, FTIR, TEM, TGA, and NMR measurements confirmed a correct surface modification and an approximate thickness of $2.82 \mathrm{~nm}$ of APTES obtained in the silanization process. Current research indicates that the conditions established from the second experimental design in the doping process of $\mathrm{TiO}_{2}$ with $\mathrm{Ag}$ (Concentration of $\mathrm{AgNO}_{3}, \mathrm{Amount}$ of $\mathrm{TiO}_{2}$, and constant $\mathrm{pH}$ ) can be applied to make an antibacterial material with a high impact on the inhibition of Staphylococcus aureus. Implementing the first experimental design and the response surface methodology indicated an increase in the $\mathrm{AgNO}_{3}$ concentration causes an enhanced microorganism inhibition. However, at the same time, the statistical significance evaluated by the Student's t-test and the p-value showed that the same variable was significant in the process, while $\mathrm{pH}$ was the least influential variable. Due to the above, a second experimental design was established, leaving the $\mathrm{pH}$ constant at 10 . For the inhibition of $S$. aureus, the $\mathrm{AgNO}_{3}$ concentration range between $20-25 \% \mathrm{w} / \mathrm{w}$ is adequate together with 7 or $8 \mathrm{~g}$ of $\mathrm{TiO}_{2}$ in 
solution. The length of the $S$. aureus zone of inhibition can be well represented by the second-order model obtained from the application of the response surface methodology, with a determination coefficient $\mathrm{R}^{2}$ of 0.82 , so the length can be predicted of the inhibition zone with up to $82 \%$ precision.

\section{Declarations}

\section{Acknowledgments}

The authors wish to thank Consejo Nacional de Ciencia y Tecnología (CONACYT) for the scholarship granted to Marco Antonio Olivares-Ramírez that allowed the fulfilment of this work. The authors express their gratitude to CONACYT for the support to J.A. González-Calderón through the "Cátedras CONACYT" program.

\section{Competing interests:}

The authors declare no competing interests.

\section{References}

1. Tekin D, Birhan D, Kiziltas H (2020) Thermal, photocatalytic, and antibacterial properties of calcinated nano- $\mathrm{TiO}_{2} /$ polymer composites. Mater Chem Phys 251:123067. https://doi.org/10.1016/j.matchemphys.2020.123067

2. Lin D, Yang Y, Wang J, Yan W, Wu Z, Chen H, Zhang Q, Wu D, Qin W, Tu Z (2020) Preparation and characterization of $\mathrm{TiO}_{2}$-Ag loaded fish gelatin-chitosan antibacterial composite film for food packaging, Int J Biol Macromol. 154:123-133 https://doi.org/10.1016/j.ijbiomac.2020.03.070

3. Soo JZ, Chai LCh, Ang BCh, Ong BH (2020) Enhancing the Antibacterial Performance of Titanium Dioxide Nanofibers by Coating with Silver Nanoparticles. ACS Appl. Nano Mater. 3(6):57435751. https://doi.org/10.1021/acsanm.0c00925

4. Betancur HCP, Hernández MV, Buitrago SR (2016) Nanopartículas para materiales antibacterianos y aplicaciones del dióxido de titanio. Rev. Cuba. Investig. Biomédicas 35(4): 387-402. ISSN 08640300. http://scielo.sld.cu/pdf/ibi/v35n4/ibi09416.pdf

\section{Zare EN, Makvandi P, Borzacchiello A, Tay FR, Ashtaricf B, Padil VVT (2019) Antimicrobial gum} biobased nanocomposites and their industrial and biomedical applications. Chem Commun. 55(99):14871-14885. https://doi.org/10.1039/C9CC08207G

6. Wang CY, Makvandi P, Zare EN, Tay FR, Niu LN (2020) Advances in Antimicrobial Organic and Inorganic Nanocompounds in Biomedicine. Adv

Ther. 3(8):2000024. https://doi.org/10.1002/adtp.202000024

7. Emam HE, Zahran MK, Ahmed HB. (2017) Generation of Biocompatible Nanogold Using $\mathrm{H}_{2} \mathrm{O}_{2}-$ Starch and Their Catalytic/Antimicrobial Activities. Eur Polym J. 90:354-367 doi: http://dx.doi.org/10.1016/j.eurpolymj.2017.03.034 
8. Ahmed HB, El-Hawary NS, Emam HE (2017) Self-assembled AuNPs for ingrain pigmentation of silk fabrics with antibacterial potency Int J Biol Macromol 105(1):720-

729. http://dx.doi.org/10.1016/j.ijbiomac.2017.07.096

9. Mazur K, Singh R, Friedrich RP, Genç H, Unterweger H, Sałasińska K, Bogucki R, Kuciel S, Cicha I (2020)The Effect of Antibacterial Particle Incorporation on the Mechanical Properties, Biodegradability, and Biocompatibility of PLA and PHBV Composites. Macromol Mater Eng 305(9):2000244. https://doi.org/10.1002/mame.202000244

10. Sharmaa R, Jafarib SM, Sharma S (2020) Antimicrobial bio-nanocomposites and their potential applications in food packaging. Food control

112:107086. https://doi.org/10.1016/j.foodcont.2020.107086

11. Emam HE (2019) Arabic Gum as Bio-Synthesizer for Ag-Au Bimetallic Nanocomposite Using Seed-Mediated Growth Technique and Its Biological Efficacy. J Polym Environ. 27:210223. https://doi.org/10.1007/s10924-018-1331-3

12. Ahmed HB, Attia MA, Farida MSE El-Dars, Emam HE (2019) Hydroxyethyl cellulose for spontaneous synthesis of antipathogenic nanostructures: (Ag \& Au) nanoparticles versus Ag-Au nano-alloy. Int J Biol Macromol. 128:214-229. https://doi.org/10.1016/j.jibiomac.2019.01.093

13. Ahmed HB, Emam HE. (2020) Environmentally exploitable biocide/fluorescent metal marker carbon quantum dots. RSC Adv.10:42916-42929 DOI: 10.1039/d0ra06383e

14. Cárdenas-Triviño G, Saludes-Betanzo MJ, Vergara-González L (2020) Bactericides Properties of Chitosan Metal Quantum Dots Microbial Pathogenicity Against E. coli, S. aureus, and S. Typhi. Int J Polym Sci. 2020:5920941.https://doi.org/10.1155/2020/5920941

15. Safardoust-Hojaghan H, Salavati-Niasari M, Amiri O, Rashki S, Ashrafi M (2021) Green synthesis, characterization and antimicrobial activity of carbon quantum dots-decorated ZnO nanoparticles. Ceram Int 47(4):51875197. https://doi.org/10.1016/j.ceramint.2020.10.097

16. Lionas V, Georgakopoulos T, Todorova N, Karapati S, Pomoni K, Trapalis C (2018) Electron transport in surface modified $\mathrm{TiO}_{2}$ nanoparticles. Mater Sci Semicond Process. 83:63-69. doi:10.1016/j.mssp.2018.04.012

17. Li Y, Tian J, Yang Ch, Hsia BS (2018) Nanocomposite film containing fibrous cellulose scaffold and $\mathrm{Ag} / \mathrm{TiO}_{2}$ nanoparticles and its antibacterial activity. Polymer (Basel) 10(10):1052. https://dx.doi.org/10.3390\%2Fpolym10101052

18. Zhang S, Liang X, Gadd GM, Zhao Q (2019) Advanced titanium dioxide-polytetrafluorethylene $\left(\mathrm{TiO}_{2}{ }^{-}\right.$ PTFE) nanocomposite coatings on stainless steel surfaces with antibacterial and anti-corrosion properties, Appl Surf Sci. 490:231-241, https://doi.org/10.1016/j.apsusc.2019.06.070.

19. Ali T, Ahmed A, Alam U, Uddin I, Tripathi P, Muneer M (2018) Enhanced photocatalytic and antibacterial activities of $\mathrm{Ag}$-doped $\mathrm{TiO}_{2}$ nanoparticles under visible light. Mater. Chem. Phys 212(15): 325-335. https://doi.org/10.1016/j.matchemphys.2018.03.052 
20. Forato F, Talebzadeh S, Rousseau N, Mevellec JY, Bujoli B, Knight DA, Queffélec C, Humbert B

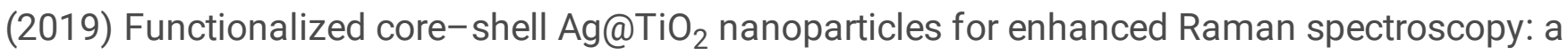
sensitive detection method for $\mathrm{Cu}(\mathrm{ii})$ ions. Phys Chem Chem Phys. 21:30663072. https://doi.org/10.1039/C8CP07504B

21. Dobrucka R, Dlugaszewska J (2018) Antimicrobial activity of the biogenically synthesized core-shell Cu@Pt nanoparticles. Saudi Pharm J. 26:643-650. https://doi.org/10.1016/j.jsps.2018.02.028

22. Haider AJ, Anbari RH, Kadhim G (2017) Exploring potential Environmental applications of $\mathrm{TiO}_{2}$ Nanoparticles. Energy Procedia, 119: 332-345. http://dx.doi.org/10.1016/j.egypro.2017.07.117

23. Kate RJ, Khalate SA, Deokate RJ (2018) Overview of nanostructured metal oxides and pure nickel oxide (NiO) electrodes for supercapacitors: A review, J Alloys Compd. 734:89-

111. https://doi.org/10.1016/j.jallcom.2017.10.262.

24. Natarajan S, Lakshmi S, Thiagarajan V, Mrudula P, Chandrasekaran N, Mukherjee A (2018) Antifouling and anti-algal effects of chitosan nanocomposite $\left(\mathrm{TiO}_{2} / \mathrm{Ag}\right)$ and pristine $\left(\mathrm{TiO}_{2}\right.$ and $\left.\mathrm{Ag}\right)$ films on marine microalgae Dunaliella salina. J. Environ. Chem. Eng 6(6): 68706880. https://doi.org/10.1016/j.jece.2018.10.050

25. Pham T, Lee B (2015) Disinfection of Staphylococcus aureus in indoor aerosols using $\mathrm{Cu}-$ $\mathrm{TiO}_{2}$ deposited on glass fiber under visible light irradiation. Journal Photochem. Photobiol. A Chem 307-308: 16-22. http://dx.doi.org/10.1016/j.jphotochem.2015.04.002

26. Tri PN, Rtimi S, Ouellet CM (2019) Nanomaterials-Based Coatings. Matthew Deans. Chennai, India

27. Vallejo W, Díaz C, Navarro K, Valle R, Arboleda JW, Romero E (2016) Estudio de la actividad antimicrobiana de películas delgadas de dióxido de titanio modificado con plata. Rev. acad. colomb. cienc. exact. fis. nat. 40(154): 69-74. http://dx.doi.org/10.18257/raccefyn.289

28. Vargas UMA, Ochoa MYH, Ortegón FY, Mosquera P, Rodríguez PJE, Camargo ARJ (2011) Nanopartículas de $\mathrm{TiO}_{2}$, fase anatasa, sintetizadas por métodos químicos. Ing. Desarrollo 29(2): 186-201. https://www.redalyc.org/pdf/852/85220757005.pdf

29. León A, Reuquen $P$, Garín C, Segura R, Vargas $P$,

Zapata P, Orihuel PA (2017) FTIR and Raman Characterization of $\mathrm{TiO}_{2}$ Nanoparticles Coated with Polyethylene Glycol as Carrier for 2-Methoxyestradiol. Appl. Sci. 7(1):49-57. doi:10.3390/app7010049

30. Hariharan D, Thangamuniyandi P, Jegatha ACh, Vasantharaja R, Selvakumar P, Sagadevan S, Pugazhendhi A, Nehru LC (2020) Enhanced photocatalysis and anticancer activity of green hydrothermal synthesized $\mathrm{Ag} @ \mathrm{TiO}_{2}$ nanoparticles. J Photochem Photobiol B Biol. 202:111636. https://doi.org/10.1016/j.jphotobiol.2019.111636.

31. Harikishore M, Sandhyarani M, Venkateswarlu K, Nellaippan TA (2014) Effect of Ag doping on Antibacterial and Photocatalytic Activity of Nanocrystalline $\mathrm{TiO}_{2}$. Procedia Mater. Sci. 6: 557566. doi: 10.1016/j.mspro.2014.07.071 
32. Natarajan S, Bhuvaneshwari M, Lakshmi DS, Mrudula P, Chandrasekaran N, Mukherjee A (2016) Antibacterial and antifouling activities of Chitosan/ $\mathrm{TiO}_{2} / \mathrm{Ag}$ NPs nanocomposite films against packaged drinkin water bacterial isolates. Environ. Sci. Pollut. Res. 1:1-

13. http://dx.doi.org/10.1007/s11356-016-7102-6

33. Afanasyev DA, Ibrayev NK, Serikov TM, Zeinidenov AK (2016) Effect of the Titanium Dioxide Shell on the Plasmon Properties of Silver Nanoparticles. Russ. J. Phys. Chem. 90(4): 833-837. doi:10.1134/S0036024416040026.

34. Seders Dietrich LA, Sahu M, Biswas P, Fein JB (2012) Experimental study of $\mathrm{TiO}_{2}$ nanoparticle adhesion to silica and Fe (III) oxide-coated silica surfaces. Chem. Geol. 332-333: 148156. http://dx.doi.org/10.1016/j.chemgeo.2012.09.043

35. Shi D, Yang H, Xue XX (2020) Preparation, Characterization and Antibacterial Properties of Cobalt doped Titania Nanomaterials. Chinese J. Chem. Eng. 28(5): 1474-

1482. https://doi.org/10.1016/j.cjche.2020.03.017

36. Nageswara T, Babji P, Ahmad N, Ahmad R, Hassan I, Ali S, Mabood F (2019) Green synthesis and structural classification of Acacia nilotica mediated-silver doped titanium oxide $\left(\mathrm{Ag} / \mathrm{TiO} \mathrm{O}_{2}\right)$ spherical nanoparticles: Assessment of its antimicrobial and anticancer activity. Saudi J. Biol. Sci. 26(7): 1385-1391. https://doi.org/10.1016/j.sjbs.2019.09.005

37. Tian F, Zhou J, Fu R, Cui Y, Zhao O, Jiao B, He Y (2020) Multicolor colorimetric detection of ochratoxin A via structure-switching aptamer and enzyme-induced metallization of gold nanorods, Food Chem. 320:126607, https://doi.org/10.1016/j.foodchem.2020.126607.

38. Xu L, Li Q, Myers M, Chen Q, Li X (2019) Application of nuclear magnetic resonance technology to carbon capture, utilization and storage: A review. J Rock Mech Geotech Eng. 11(4):892908. https://doi.org/10.1016/j.jrmge.2019.01.003

39. Hassanien AS, Khatoon UT (2019) Synthesis and characterization of stable silver nanoparticles, AgNPs: Discussion on the applications of Ag-NPs as antimicrobial agents. Phys B Phys Condens Matter. 554:21-30. https://doi.org/10.1016/j.physb.2018.11.004

40. Dada AO, Inyinbor AA, Idu El, Bello OM, Oluyori AP, Adelani-Akande TA, Okunola AA, Dada O (2018) Effect of operational parameters, characterization and antibacterial studies of green synthesis of silver nanoparticles using Tithonia diversifolia. PeerJ.

30:6:e5865. https://doi.org/10.7717/peerj.5865

41. López-Zamora L, Martínez-Martínez HN, González-Calderón JA (2018) Improvement of the colloidal stability of titanium dioxide particles in water through silicon based coupling agent. Mater Chem Phys. 217:285-290. https://doi.org/10.1016/j.matchemphys.2018.06.063

42. Qiao B, Wang T, Gao H, Jin Y (2015) High density silanization of nano-silica particles using yaminopropyltriethoxysilane (APTES). Appl Surf Sci. 351:646654. https://doi.org/10.1016/j.apsusc.2015.05.174

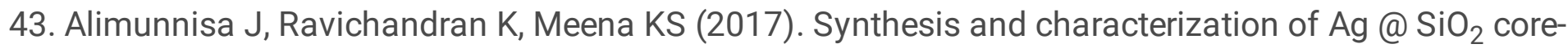
shell nanoparticles for antibacterial and environmental applications. J Mol Liq. 231:281-287, 2017. 
44. Quiñones-Jurado ZV, Waldo-Mendoza MA, Aguilera-Bandin HM, Villabona-Leal EG, CervantesGonzález E, Pérez E (2014) Silver Nanoparticles Supported on $\mathrm{TiO}_{2}$ and Their Antibacterial Properties: Effect of Surface Confinement and Nonexistence of Plasmon Resonance. Mater Sci Appl. 5: 895-903. http://dx.doi.org/10.4236/msa.2014.512091

45. Yusoff RB, Takagi H, Nakagaito AN (2016) Tensile and flexural properties of polylactic acid-based hybrid green composites reinforced by kenaf, bamboo and coir fibers. Ind Crops Prod. 94:562-573. https://doi.org/10.1016/j.indcrop.2016.09.017

46. Mallegni N, Phuong TV, Coltelli MB, Cinelli P, Lazzeri A (2018) Poly(lactic acid) (PLA) based tear resistant and biodegradable flexible films by blown film extrusion. Materials 11(1):148. http://dx.doi.org/10.3390/ma11010148

47. Gordobil O, Delucis R, Egüés I, Labidi J (2015) Kraft lignin as filler in PLA to improve ductility and thermal properties. Ind Crops Prod. 72:46-53. https://doi.org/10.1016/j.indcrop.2015.01.055

48. Kodal M, Wis AA, Ozkoc G (2018) The mechanical, thermal and morphological properties of $\mathrm{Y}^{-}$ irradiated PLA/TAIC and PLA/OvPOSS. Radiat Phys Chem 153:214-

225. https://doi. org/10.1016/j.radphyschem.2018.10.018

49. Chi H, Songa Sh, Luoa M, Zhanga Ch, Lia W, Lib L, Qin Y (2019) Effect of PLA nanocomposite films containing bergamot essential oil, $\mathrm{TiO}_{2}$ nanoparticles, and Ag nanoparticles on shelf life of mangoes. Sci Hortic. 249:192-198 https://doi.org/10.1016/j.scienta.2019.01.059

50. Li W, Zhang C, Chi H et al (2017) Development of antimicrobial packaging film made from poly(lactic acid) incorporating titanium dioxide and silver nanoparticles. Molecules. 22:11701184. https://doi.org/10.3390/molecules22071170

51. Muller CMO, Laurindo JB, Yamashita F (2011) Effect of nanoclay incorporation method on mechanical and water vapor barrier properties of starch-based films. Ind Crops Prod. 33:605-610. https://doi.org/10.1016/j.indcrop.2010.12.021

52. Vallejo-Montesinos J, Gámez-Cordero J, Zarraga R, Pérez Pérez MC, Gonzalez-Calderon JA (2020) Influence of the surface modification of titanium nanodots deposition and its effect under the properties of starch-chitosan (SC) films. Polym. Bull. 77(1): 107-133. DOI: 10.1007/s00289-01902740-z

53. Shebi A, Lisa S (2019) Evaluation of biocompatibility and bactericidal activity of hierarchically porous PLA-TiO2 nanocomposite films fabricated by breath-figure method. Mater Chem Phys. 2030:308-318. https://doi.org/10.1016/j.matchemphys.2019.03.045

54. Kalayci OA, Cömert FB, Hazer B et al (2010) Synthesis, characterization, and antibacterial activity of metal nanoparticles embedded into amphiphilic comb-type graft copolymers. Polym Bull 65:215226. https://doi.org/10.1007/s00289-009-0196-y

55. Li B, Webster TJ (2018) Bacteria antibiotic resistance: New challenges and opportunities for implantassociated orthopedic infections. J. Orthop. Res. 36:22-32. https://doi.org/10.1002/jor.23656

56. Kavanagh N, Ryan EJ, Widaa A, Sexton G, Fennell J, O'Rourke S, Cahill KC, Kearney CJ, O'Brien FJ, Kerrigan SW (2018) Staphylococcal osteomyelitis: Disease progression, treatment challenges, and 
future directions. Clin. Microbiol. Rev. 31:e00084-17. https://doi.org/10.1128/cmr.00084-17

57. Shaikh S, Nazam N, Rizvi SM, Ahmad K, Baig MH, Lee EJ, Choi I (2019) Mechanistic insights into the antimicrobial actions of metallic nanoparticles and their implications for multidrug resistance. Int $\mathrm{J}$ Mol Sci. 20:2468. https://dx.doi.org/10.3390\%2Fijms20102468

58. Segura GEA, Olmos D, Lorente MG, Vélaz I. González-Benito J (2018) Preparation and Characterization of Polymer Composite Materials Based on $\mathrm{PLA} / \mathrm{TiO}_{2}$ for Antibacterial Packaging Polymers.10:1365; doi:10.3390/polym10121365

59. Arrieta MP, Samper MD, Aldas M, López J (2017) On the use of PLA-PHB blends for sustainable food packaging applications. Materials. 10:1008. https://doi.org/10.3390/ma10091008

60. Montgomery DC (2019). Design and analysis of experiments. John Wiley \& Sons, USA. pp 408-477

61. Gonzalez-Calderon JA, López-Esparza R, Saldivar-Guerrero R, Almendarez-Camarillo A (2018) Improvement in the energy dissipation capacity of polypropylene composites through a surface modi fi cation of titanium dioxide particles with a dicarboxylic acid. Thermochim. Acta 664: 48-

56. https://doi.org/10.1016/j.tca.2018.04.008

62. González-Rodríguez V, Zapata-Tello DL, Vallejo-Monteisnos J, Zárraga Núñez R, Gonzalez-Calderon JA, Pérez E (2009) Improving titanium dioxide dispersion in water through surface functionalization by a dicarboxylic acid. J. Dispers. Sci. Technol. 1: 1039-

1045. https://doi.org/10.1080/01932691.2018.1496828

63. Bauer AW, Kirby WM, Sherris JC, M. Turck M (1966) Antibiotic susceptibility testing by a standardized single disk method. Am J Clin Pathol 45(4): 493-496. https://doi.org/10.1093/ajcp/45.4_ts.493

64. Haghighat N, Vatanpour V, Sheydaei M, Nikjavan Z (2020) Preparation of a novel polyvinyl chloride (PVC) ultrafiltration membrane modified with $\mathrm{Ag} / \mathrm{TiO}_{2}$ nanoparticle with enhanced hydrophilicity and antibacterial activities. Sep. Purif. Technol. 237:

116374. https://doi.org/10.1016/j.seppur.2019.116374

65. Karagoz S, Burak N, Sakir M, Salem S, Serdar M, Sahmetlioglu E, Ceylan A, Yilmaz E (2020) Synthesis of $\mathrm{Ag}$ and $\mathrm{TiO}_{2}$ modified polycaprolactone electrospun nanofibers ( $\mathrm{PCL} / \mathrm{TiO}_{2}-\mathrm{Ag} \mathrm{NFs}$ ) as a multifunctional material for SERS, photocatalysis and antibacterial applications. Ecotoxicol. Environ. Saf. 188(30): 109856. https://doi.org/10.1016/j.ecoenv.2019.109856

66. Ranjbar-Mohammadi M, Rahimdokht M, Pajootan E (2019) Low cost hydrogels based on gum Tragacanth and TiO2 nanoparticles: characterization and RBFNN modelling of methylene blue dye removal Int J Biol Macromol. 134:967-975. https://doi.org/10.1016/j.jbiomac.2019.05.026

67. Mohammadi A, Aliakbarzadeh KA (2017) Methylene Blue Removal Using Surface-Modified $\mathrm{TiO}_{2}$ Nanoparticles: A Comparative Study on Adsorption and Photocatalytic Degradation J. Water Environ. Nanotechnol. 2(2): 118-128. DOI: 10.22090/jwent.2017.02.007

68. Chen Q, Yakovlev NL (2010) Adsorption and interaction of organosilanes on $\mathrm{TiO}_{2}$ nanoparticles. Appl. Surf. Sci. 257(4): 1395-1400. doi:10.1016/j.apsusc.2010.08.036 
Tables

Table 1 Levels of the experimental design of the variables studied

\begin{tabular}{|c|c|c|c|c|c|c|c|}
\hline \multirow{3}{*}{$\mathrm{N}^{\circ}$} & \multicolumn{3}{|c|}{ ENCODE VARIABLE } & \multicolumn{3}{|c|}{ NATURAL VARIABLE } & \multirow{2}{*}{\begin{tabular}{|c|} 
RESPONSE \\
S. aureus halo
\end{tabular}} \\
\hline & $\mathrm{X} 1$ & $\begin{array}{c}\mathrm{X} 2 \\
(\% \mathrm{p} / \mathrm{p})\end{array}$ & $\begin{array}{c}\text { X3 } \\
(\mathrm{g} / 250 \mathrm{~mL})\end{array}$ & $\mathrm{X} 1$ & $\begin{array}{c}\mathrm{X} 2 \\
(\% \mathrm{p} / \mathrm{p})\end{array}$ & $\begin{array}{c}\text { X3 } \\
(\mathrm{g} / 250 \mathrm{~mL})\end{array}$ & \\
\hline & & & & & & & $(\mathrm{mm})$ \\
\hline 1 & -1 & -1 & -1 & 8.00 & 4.00 & 3.00 & 8.56 \\
\hline 2 & 1 & -1 & -1 & 12.00 & 4.00 & 3.00 & 8.27 \\
\hline 3 & -1 & 1 & -1 & 8.00 & 10.00 & 3.00 & 8.25 \\
\hline 4 & 1 & 1 & -1 & 12.00 & 10.00 & 3.00 & 9.37 \\
\hline 5 & -1 & -1 & 1 & 8.00 & 4.00 & 7.00 & 8.42 \\
\hline 6 & 1 & -1 & 1 & 12.00 & 4.00 & 7.00 & 7.32 \\
\hline 7 & -1 & 1 & 1 & 8.00 & 10.00 & 7.00 & 9.56 \\
\hline 8 & 1 & 1 & 1 & 12.00 & 10.00 & 7.00 & 10.10 \\
\hline 9 & -1.68179 & 0 & 0 & 6.64 & 7.00 & 5.00 & 7.88 \\
\hline 10 & 1.68179 & 0 & 0 & 13.36 & 7.00 & 5.00 & 7.75 \\
\hline 11 & 0 & -1.68179 & 0 & 10.00 & 1.95 & 5.00 & 9.86 \\
\hline 12 & 0 & 1.68179 & 0 & 10.00 & 12.05 & 5.00 & 11.17 \\
\hline 13 & 0 & 0 & -1.68179 & 10.00 & 7.00 & 1.64 & 8.96 \\
\hline 14 & 0 & 0 & 1.68179 & 10.00 & 7.00 & 8.36 & 8.63 \\
\hline 15 & 0 & 0 & 0 & 10.00 & 7.00 & 5.00 & 10.50 \\
\hline 16 & 0 & 0 & 0 & 10.00 & 7.00 & 5.00 & 9.58 \\
\hline 17 & 0 & 0 & 0 & 10.00 & 7.00 & 5.00 & 9.15 \\
\hline 18 & 0 & 0 & 0 & 10.00 & 7.00 & 5.00 & 10.88 \\
\hline 19 & 0 & 0 & 0 & 10.00 & 7.00 & 5.00 & 11.26 \\
\hline 20 & 0 & 0 & 0 & 10.00 & 7.00 & 5.00 & 10.62 \\
\hline
\end{tabular}

Table 2 Results of the response variable for Staphylococcus aureus 


\begin{tabular}{|c|c|c|c|c|}
\hline \multirow[t]{2}{*}{$\mathrm{N}^{\circ}$} & \multicolumn{3}{|c|}{ ENCODE VARIABLE } & \multirow{2}{*}{$\begin{array}{c}\text { RESPONSE } \\
\begin{array}{c}\text { S. aureus halo } \\
(\mathrm{mm})\end{array}\end{array}$} \\
\hline & $\mathrm{X}_{1}$ & $\begin{array}{c}\mathrm{X}_{2} \\
(\% \mathrm{p} / \mathrm{p})\end{array}$ & $\begin{array}{c}\mathrm{X}_{3} \\
(\mathrm{~g} / 250 \mathrm{~mL})\end{array}$ & \\
\hline 1 & -1 & -1 & -1 & 8.56 \\
\hline 2 & 1 & -1 & -1 & 8.27 \\
\hline 3 & -1 & 1 & -1 & 8.25 \\
\hline 4 & 1 & 1 & -1 & 9.37 \\
\hline 5 & -1 & -1 & 1 & 8.42 \\
\hline 6 & 1 & -1 & 1 & 7.32 \\
\hline 7 & -1 & 1 & 1 & 9.56 \\
\hline 8 & 1 & 1 & 1 & 10.10 \\
\hline 9 & -1.68179 & 0 & 0 & 7.88 \\
\hline 10 & 1.68179 & 0 & 0 & 7.75 \\
\hline 11 & 0 & -1.68179 & 0 & 9.86 \\
\hline 12 & 0 & 1.68179 & 0 & 11.17 \\
\hline 13 & 0 & 0 & -1.68179 & 8.96 \\
\hline 14 & 0 & 0 & 1.68179 & 8.63 \\
\hline 15 & 0 & 0 & 0 & 10.50 \\
\hline 16 & 0 & 0 & 0 & 9.58 \\
\hline 17 & 0 & 0 & 0 & 9.15 \\
\hline 18 & 0 & 0 & 0 & 10.88 \\
\hline 19 & 0 & 0 & 0 & 11.26 \\
\hline 20 & 0 & 0 & 0 & 10.62 \\
\hline
\end{tabular}

Table 3 Significance of the regression coefficients of the Staphylococcus aureus evaluation

\begin{tabular}{|l|l|l|l|}
\hline Variable & $\begin{array}{c}\text { Regression } \\
\text { coefficient }\end{array}$ & $\begin{array}{c}\text { T-student } \\
\text { value }\end{array}$ & $\begin{array}{c}p \\
\text { value }\end{array}$ \\
\hline Interception & -13.45 & 41.63 & \\
\hline$X_{1}$ & 4.468 & 0.02 & 0.984 \\
\hline$X_{2}$ & -0.818 & 3.07 & 0.012 \\
\hline$X_{3}$ & 1.472 & 0.17 & 0.867 \\
\hline$X_{1}^{2}$ & -0.2347 & -5.85 & 0.000 \\
\hline$X_{2}^{2}$ & 0.0018 & 0.10 & 0.921 \\
\hline$X_{3}^{2}$ & -0.1479 & -3.69 & 0.004 \\
\hline$X_{1} X_{2}$ & 0.0636 & 1.77 & 0.107 \\
\hline$X_{1} X_{3}$ & -0.0434 & -0.81 & 0.439 \\
\hline$X_{2} X_{3}$ & 0.0650 & 1.81 & 0.100 \\
\hline
\end{tabular}

Table 4 Results of the response variable for Staphylococcus aureus from the CCD experimental design of two factors 


\begin{tabular}{|c|c|c|c|c|c|}
\hline \multirow[b]{2}{*}{$\mathrm{N}^{\circ}$} & \multicolumn{2}{|c|}{ ENCODED VARIABLE } & \multicolumn{2}{|c|}{ NATURAL VARIABLE } & \multirow{2}{*}{$\begin{array}{l}\text { RESPONSE } \\
\text { y, S. aureus } \\
\text { halo (mm) }\end{array}$} \\
\hline & $\begin{array}{c}\mathrm{X} 1 \\
(\% \mathrm{p} / \mathrm{p})\end{array}$ & $\begin{array}{c}\mathrm{X} 2 \\
(\mathrm{~g} / 250 \mathrm{~mL})\end{array}$ & $\begin{array}{c}\mathrm{X} 1 \\
(\% \mathrm{p} / \mathrm{p})\end{array}$ & $\begin{array}{c}\mathrm{X} 2 \\
(\mathrm{~g} / 250 \mathrm{~mL})\end{array}$ & \\
\hline 1 & -1.00000 & -1.00000 & 25.0000 & 3.0000 & 13.16 \\
\hline 2 & 1.00000 & -1.00000 & 45.0000 & 3.0000 & 19.59 \\
\hline 3 & -1.00000 & 1.00000 & 25.0000 & 7.0000 & 20.40 \\
\hline 4 & 1.00000 & 1.00000 & 45.0000 & 7.0000 & 16.80 \\
\hline 5 & $-\sqrt{2}$ & 0.00000 & 20.8579 & 5.0000 & 13.98 \\
\hline 6 & $\sqrt{ } 2$ & 0.00000 & 49.1421 & 5.0000 & 22.09 \\
\hline 7 & 0.00000 & $-\sqrt{2}$ & 35.0000 & 2.17157 & 18.34 \\
\hline 8 & 0.00000 & $\sqrt{2}$ & 35.0000 & 7.82843 & 16.50 \\
\hline 9 & 0.00000 & 0.00000 & 35.0000 & 5.0000 & 15.26 \\
\hline 10 & 0.00000 & 0.00000 & 35.0000 & 5.0000 & 14.93 \\
\hline 11 & 0.00000 & 0.00000 & 35.0000 & 5.0000 & 14.29 \\
\hline 12 & 0.00000 & 0.00000 & 35.0000 & 5.0000 & 14.13 \\
\hline 13 & 0.00000 & 0.00000 & 35.0000 & 5.0000 & 14.17 \\
\hline
\end{tabular}

Table 5 Significance of the regression coefficients of the evaluation of Staphylococcus aureus from the CCD experimental design of two factors

\begin{tabular}{|l|c|c|c|}
\hline Variable & $\begin{array}{c}\text { Regression } \\
\text { coefficient }\end{array}$ & $\begin{array}{c}\text { T-student } \\
\text { value }\end{array}$ & $\begin{array}{c}p \\
\text { value }\end{array}$ \\
\hline Interception & 14.9 & 21.08 & \\
\hline$X_{1}$ & -0.370 & 3.27 & 0.014 \\
\hline$X_{2}$ & 1.07 & 0.42 & 0.686 \\
\hline$X_{1}^{2}$ & 0.01678 & 2.87 & 0.024 \\
\hline$X_{2}^{2}$ & 0.343 & 2.34 & 0.052 \\
\hline$X_{1} X_{2}$ & -0.1253 & -3.25 & 0.014 \\
\hline
\end{tabular}

Table 6 TEM / EDS chemical analysis of Ag-doped and modified $\mathrm{TiO}_{2}$ particles from experimental unit 6 and 1

\begin{tabular}{|l|c|c|}
\hline & Experimental unit (6) & Experimental unit (1) \\
\hline Element & \% Weight & \% Weight \\
\hline Silver $(\mathrm{Ag})$ & 21.7 & 16.2 \\
\hline Oxygen $\left(\mathrm{O}_{2}\right)$ & 28.6 & 37.7 \\
\hline Titanium $(\mathrm{Ti})$ & 49.7 & 46.1 \\
\hline
\end{tabular}



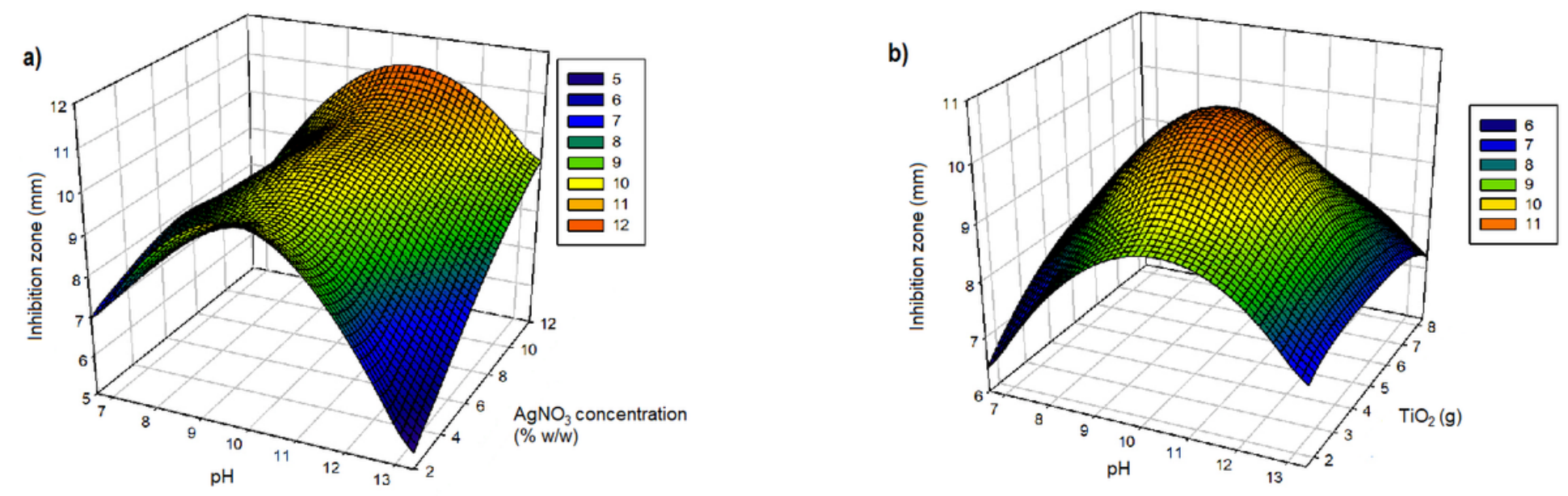

c)

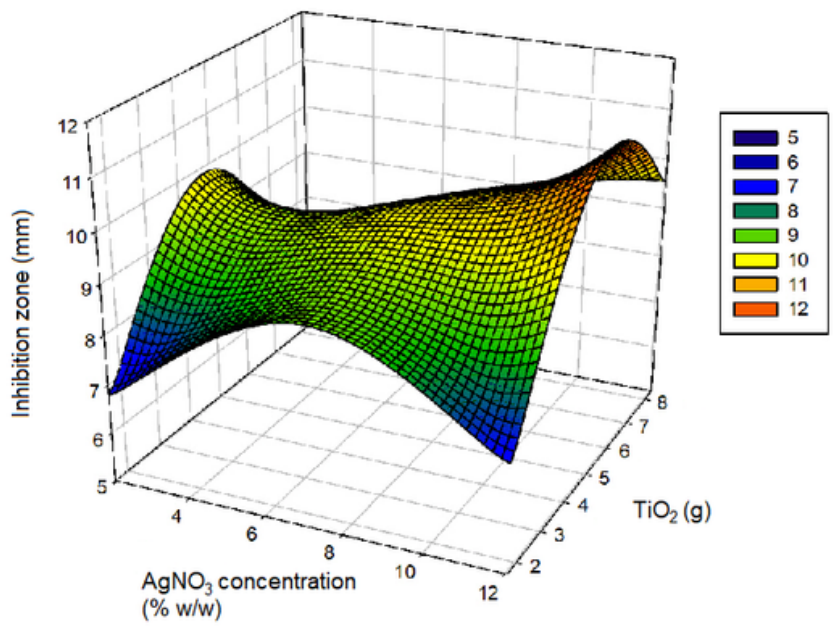

Figure 1

Response surfaces of the evaluation of S. aureus, a) pH vs. AgNO3 concentration (\% w/w), b) pH vs. TiO2 solids (g), c) AgNO3 concentration (\% w/w) vs. TiO2 solids (g) 
a)

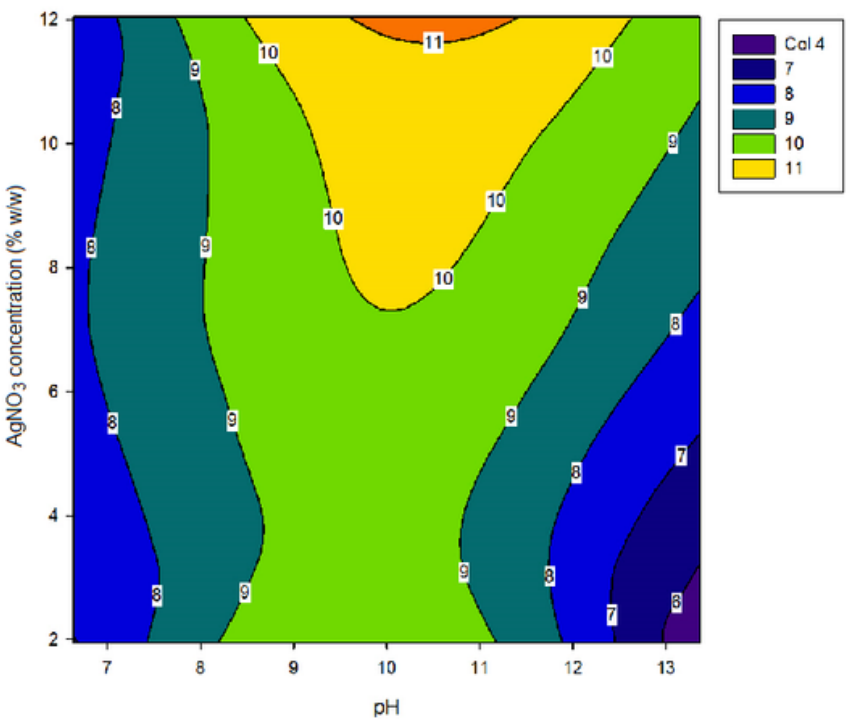

b)

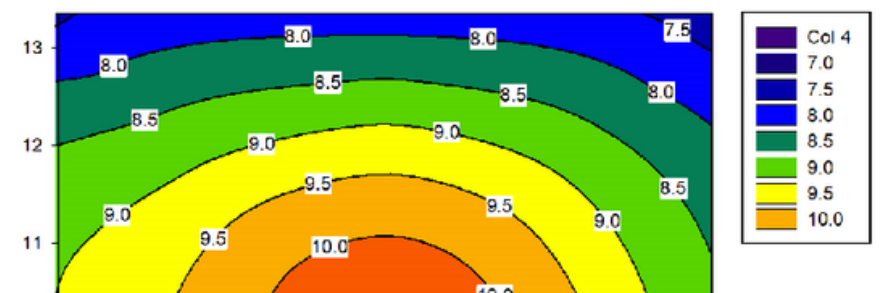

c)
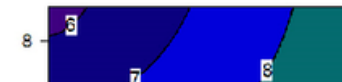
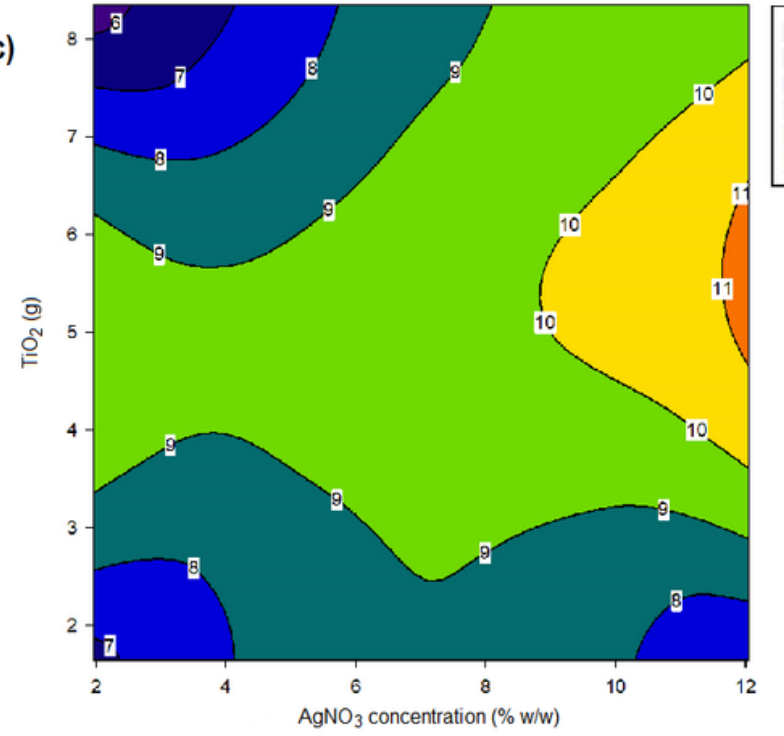

Figure 2

Contour graphs of the evaluation of S. aureus, a) pH vs. AgNO3 concentration (\%w/w), b) TiO2 solids (g) vs. $\mathrm{pH}, \mathrm{c}) \mathrm{AgNO} 3$ concentration (\% w/w) vs. TiO2 solids ( $\mathrm{g}$ ) 


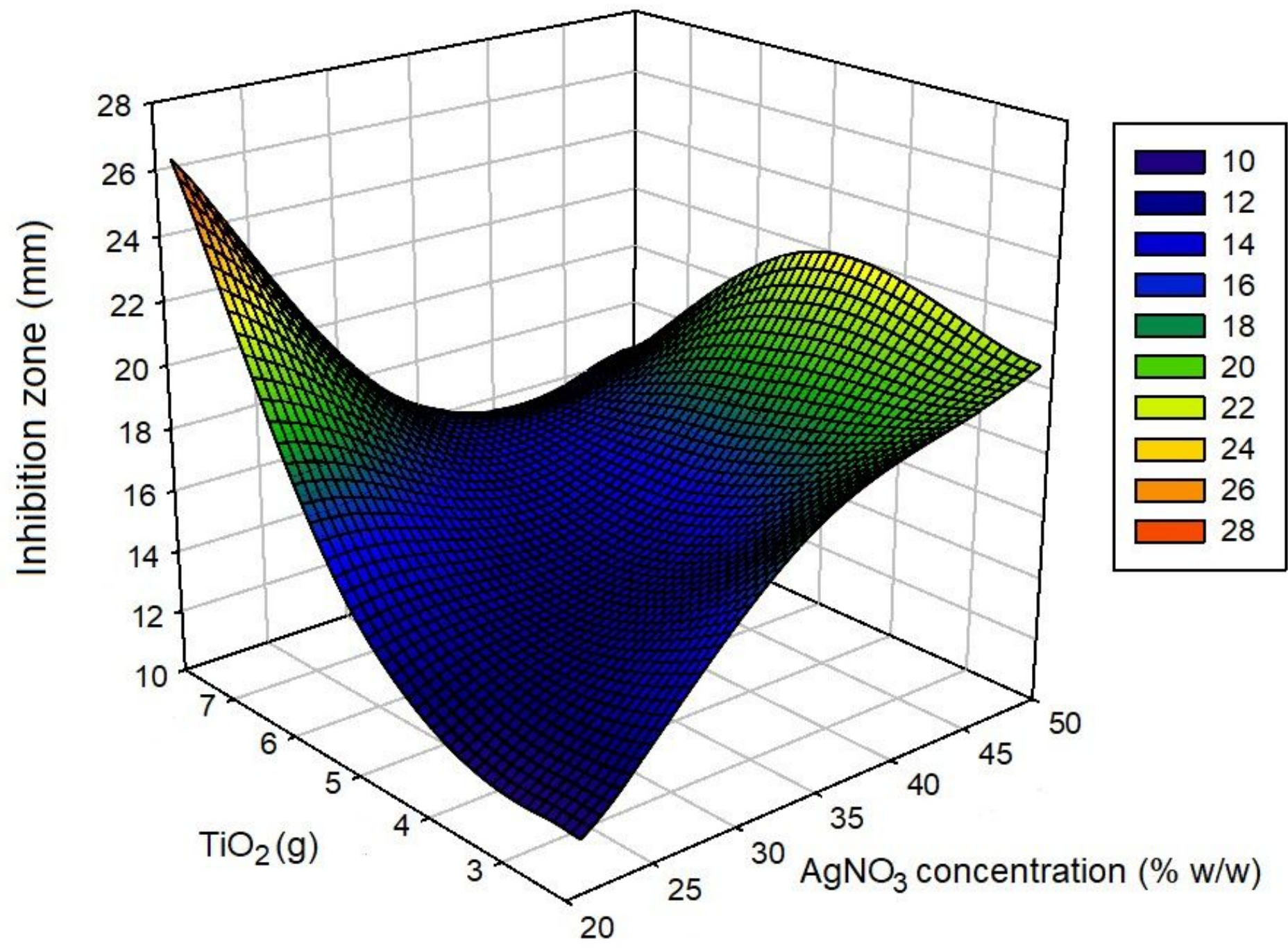

Figure 3

Response surface of the evaluation of S. aureus, AgNO3 concentration (\% w/w) vs. TiO2 solids (g) 


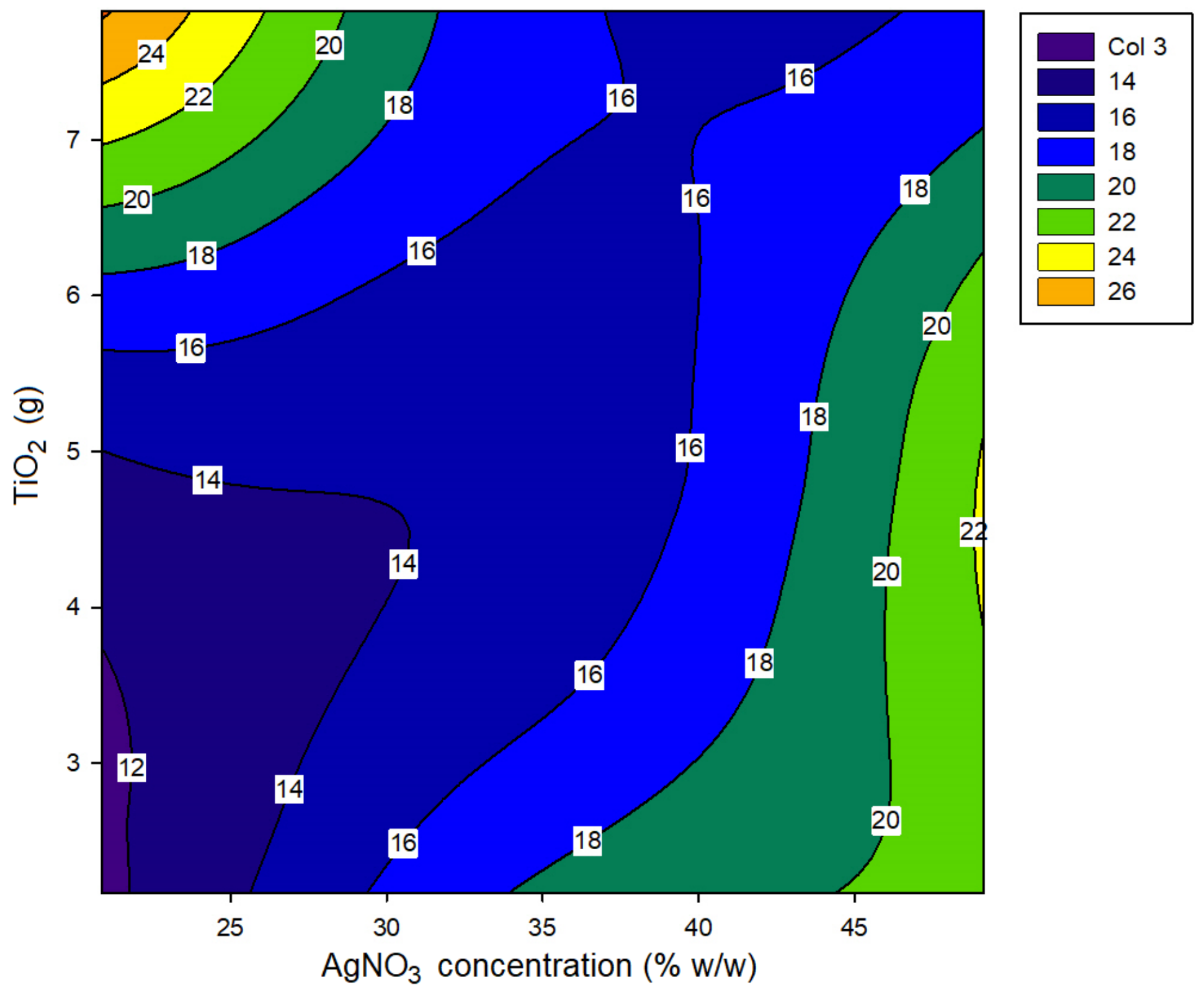

Figure 4

Contour graph of the evaluation of S. aureus, AgNO3 concentration (\% w/w) vs. TiO2 solids (g) 

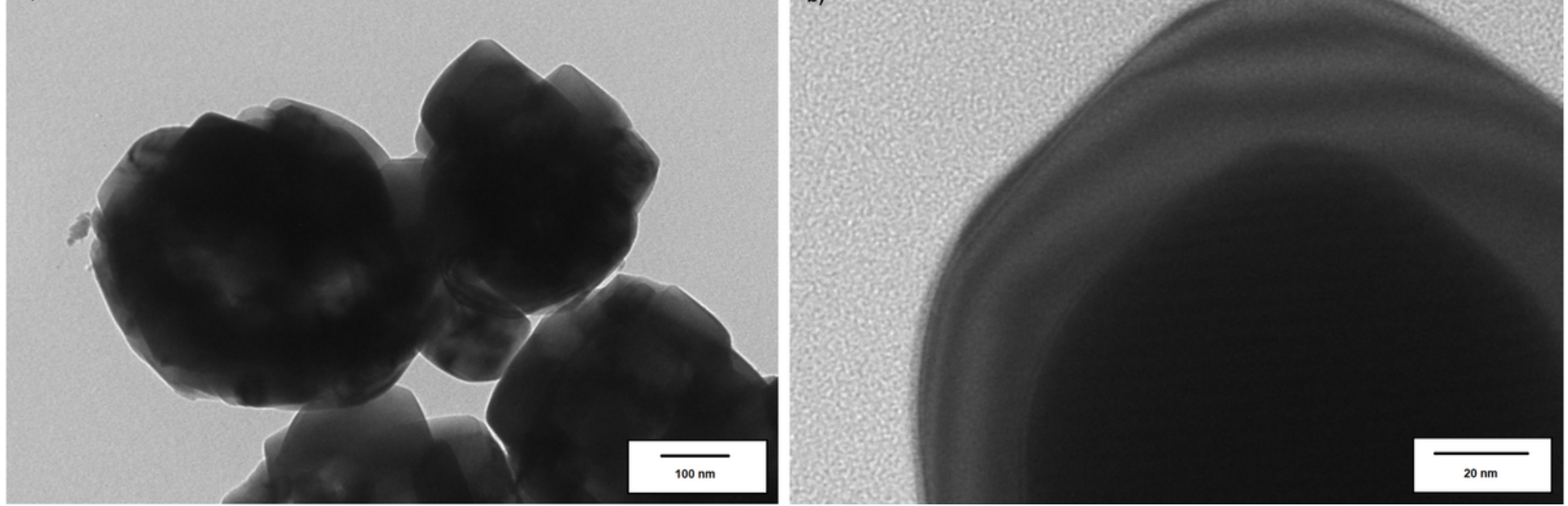

Figure 6

TEM micrographs a) TiO2, b) Silanized TiO2 (modified)

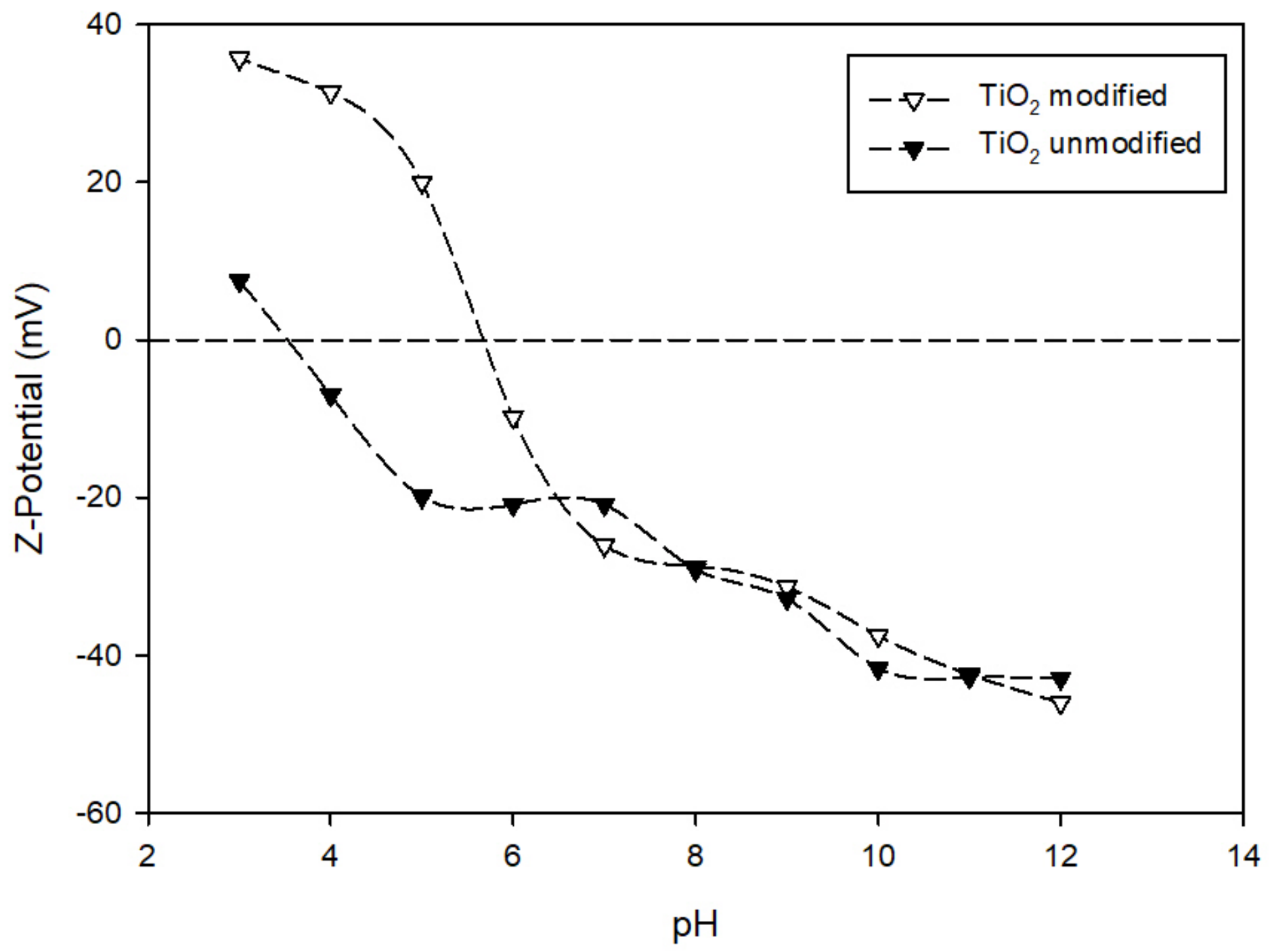


Figure 7

Z potential of the NPs of $\mathrm{TiO} 2$ and modified $\mathrm{TiO} 2$

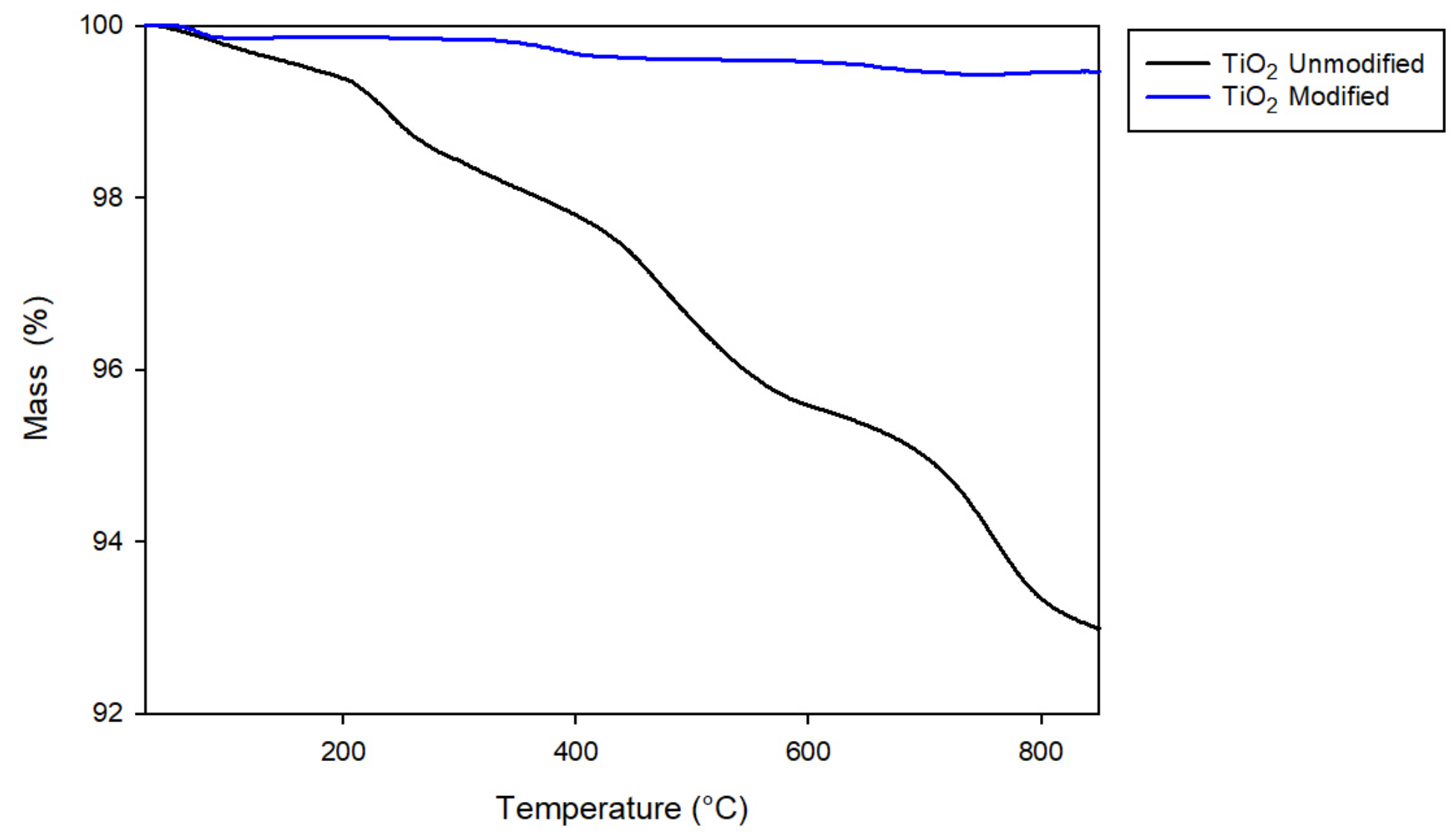

Figure 8

Thermo-gravimetric analysis of $\mathrm{TiO} 2$ and silanized TiO2 (modified) 


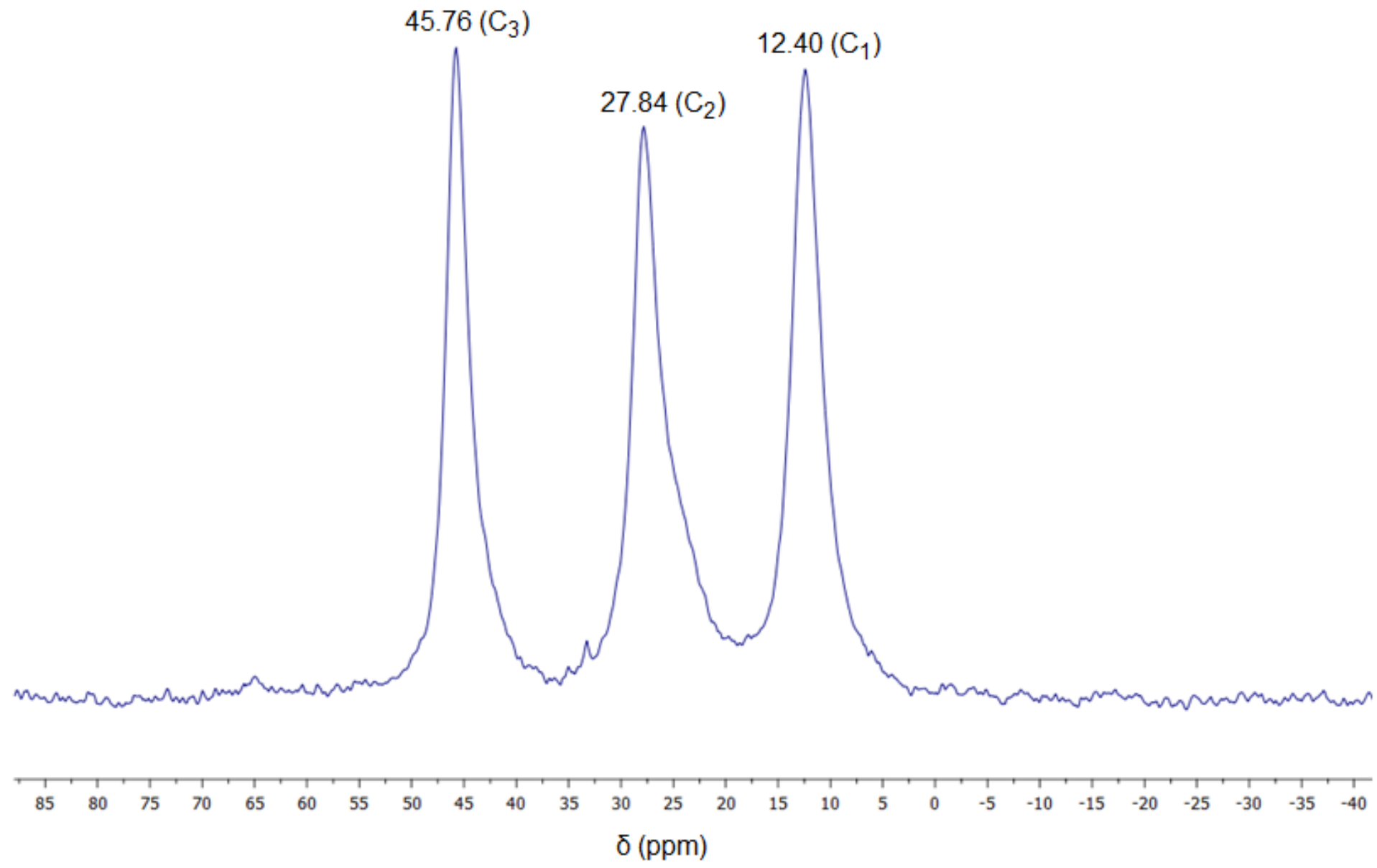

Figure 9

NMR spectrum for $13 \mathrm{C}$ 


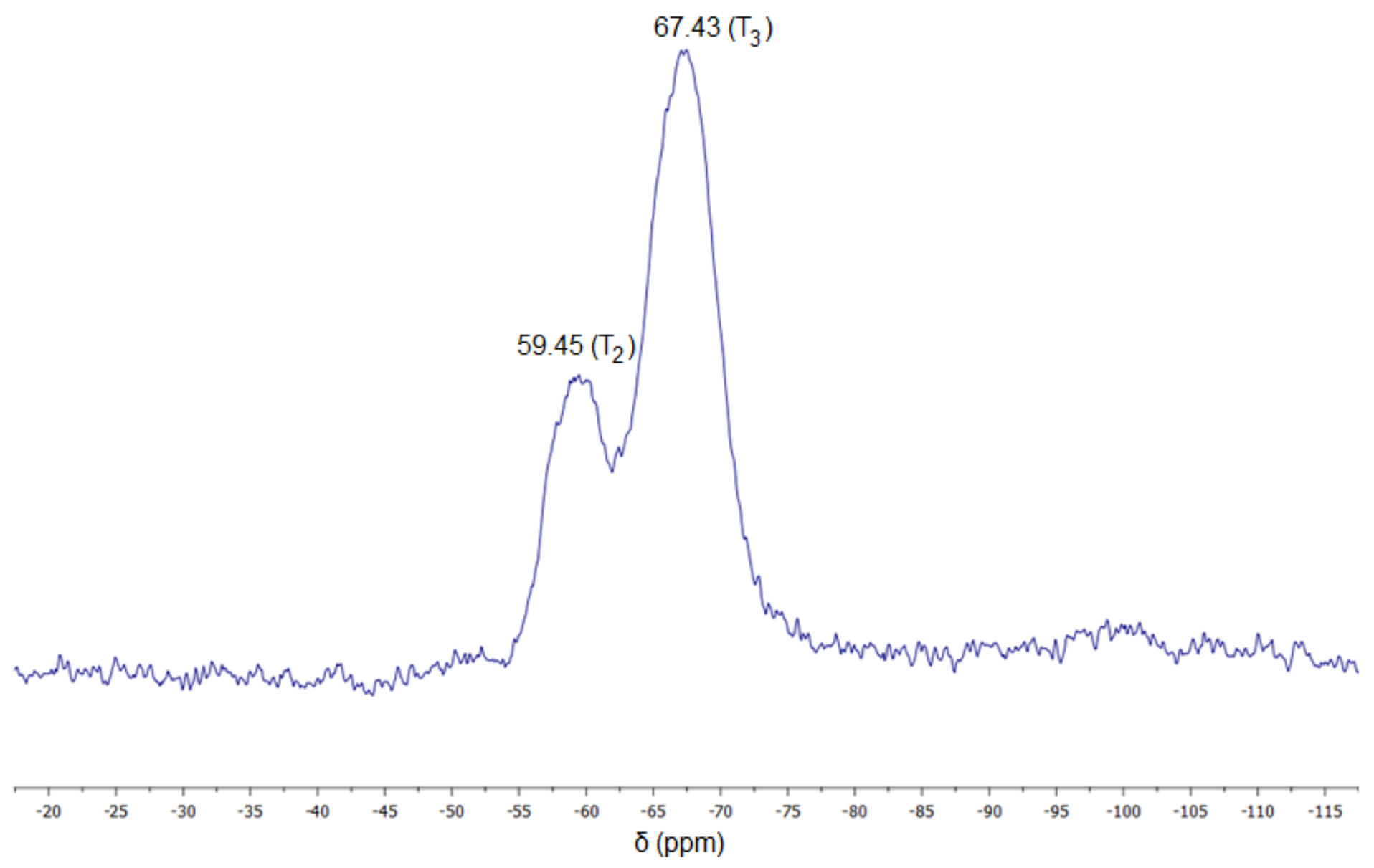

Figure 10

NMR spectrum for $29 \mathrm{Si}$
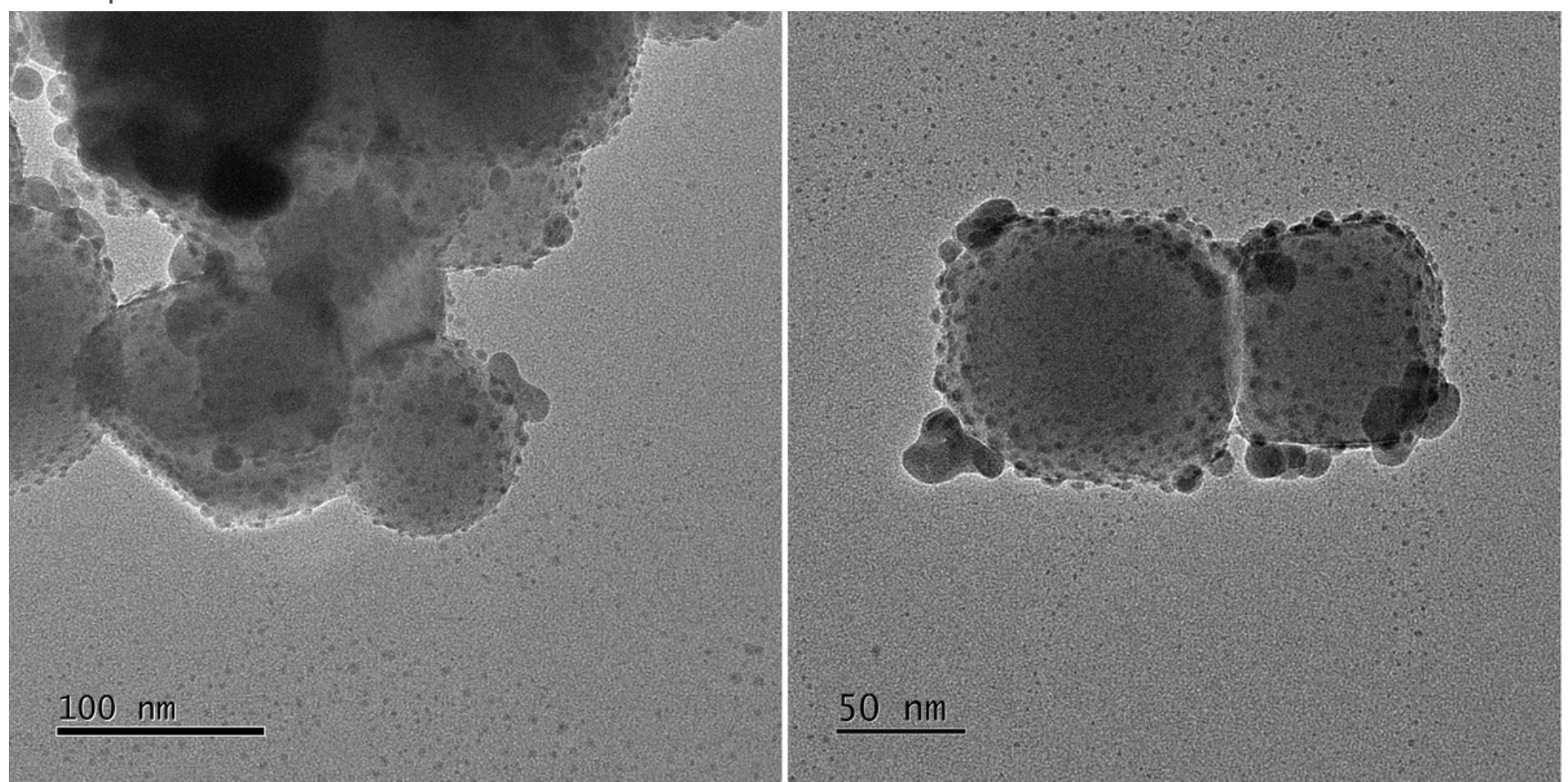
Figure 11

TEM micrograph of CDC Two-Factor experimental unit 6
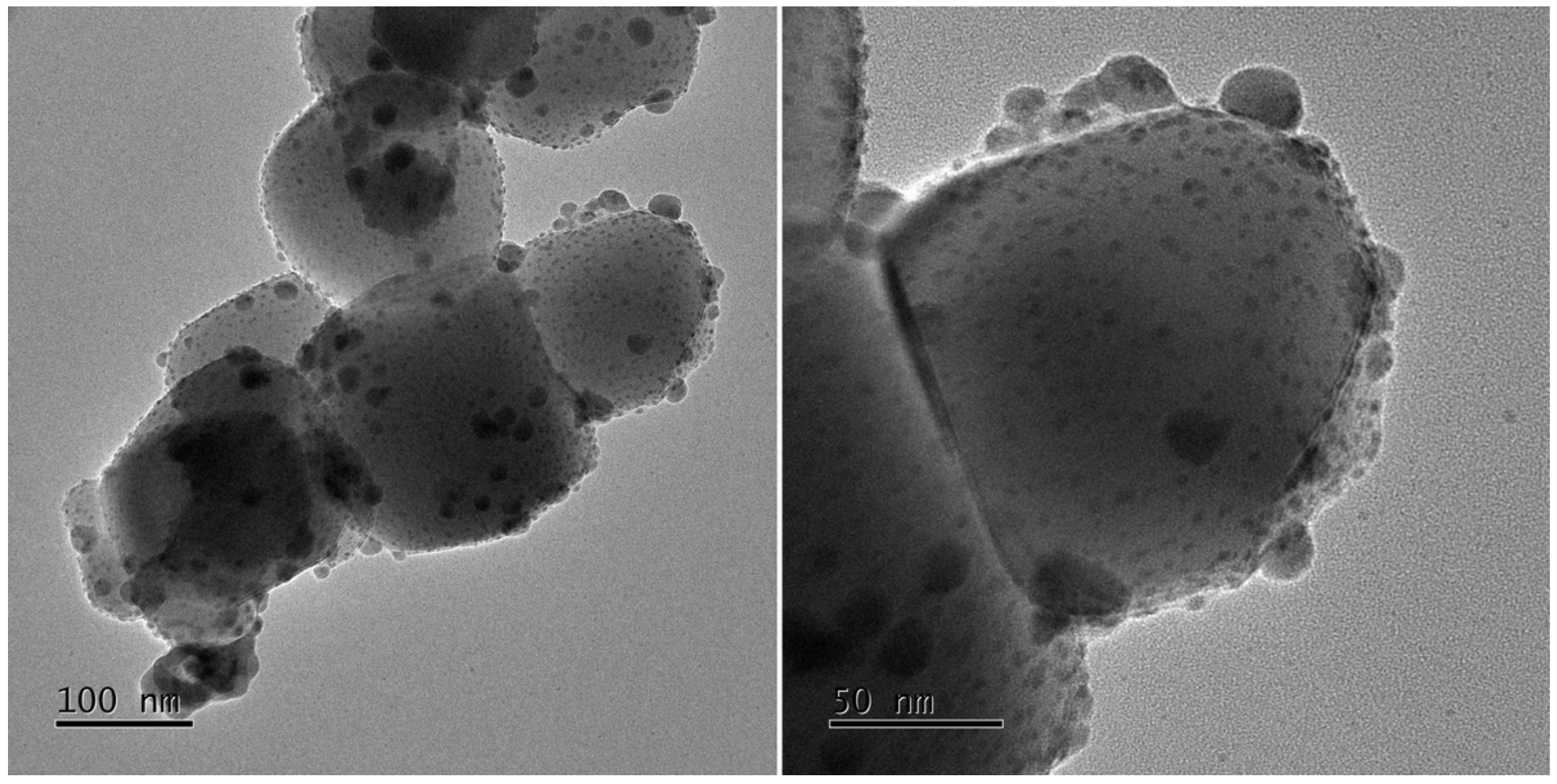

\section{Figure 12}

TEM micrograph of CDC Two-Factor experimental unit 1
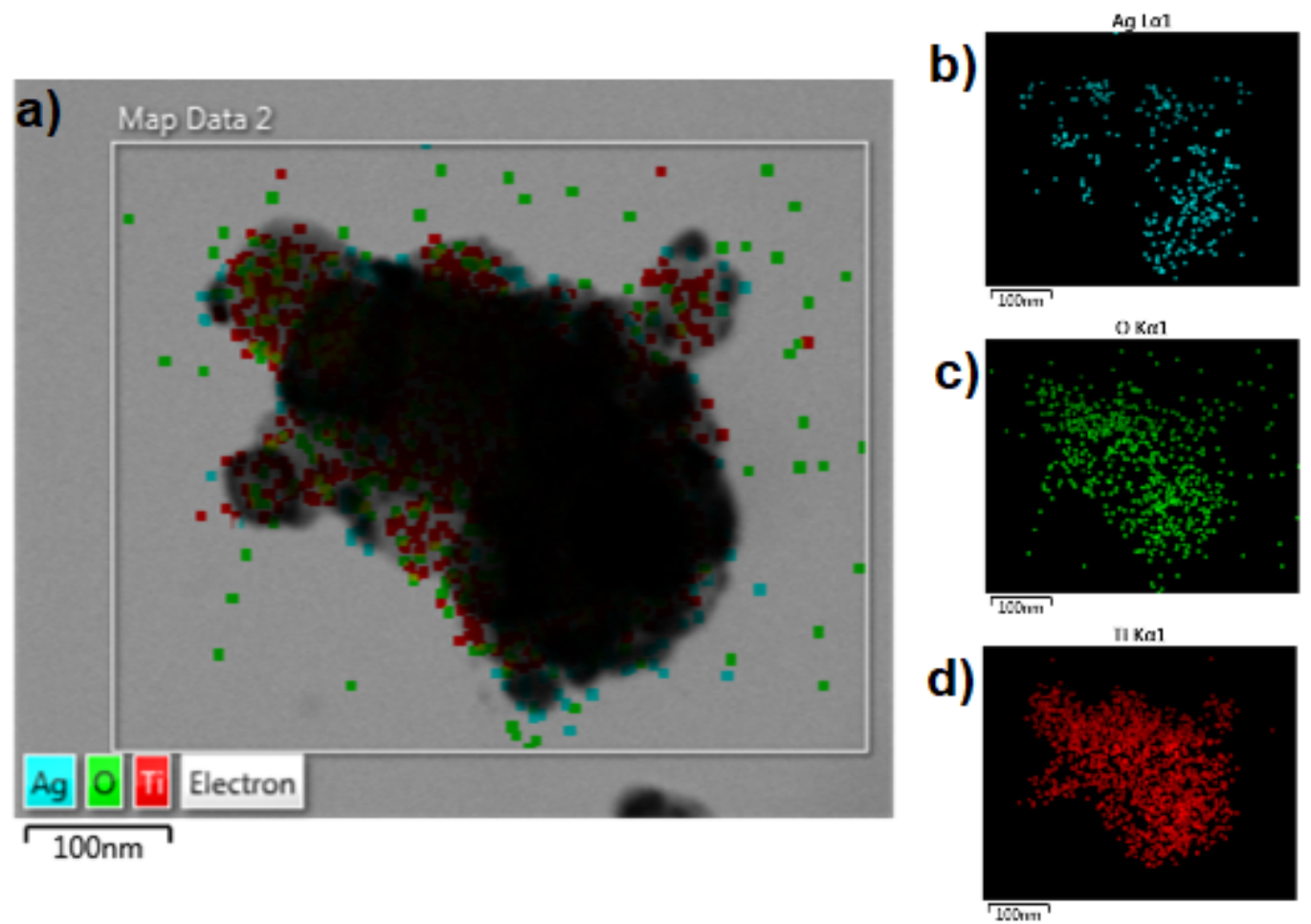

Figure 13 
TEM/EDS analysis of the CCD experimental unit 6 of two factors: a) Ag/ TiO2 morphology, b) Ag distribution, c) 02 distribution, and d) Ti distribution
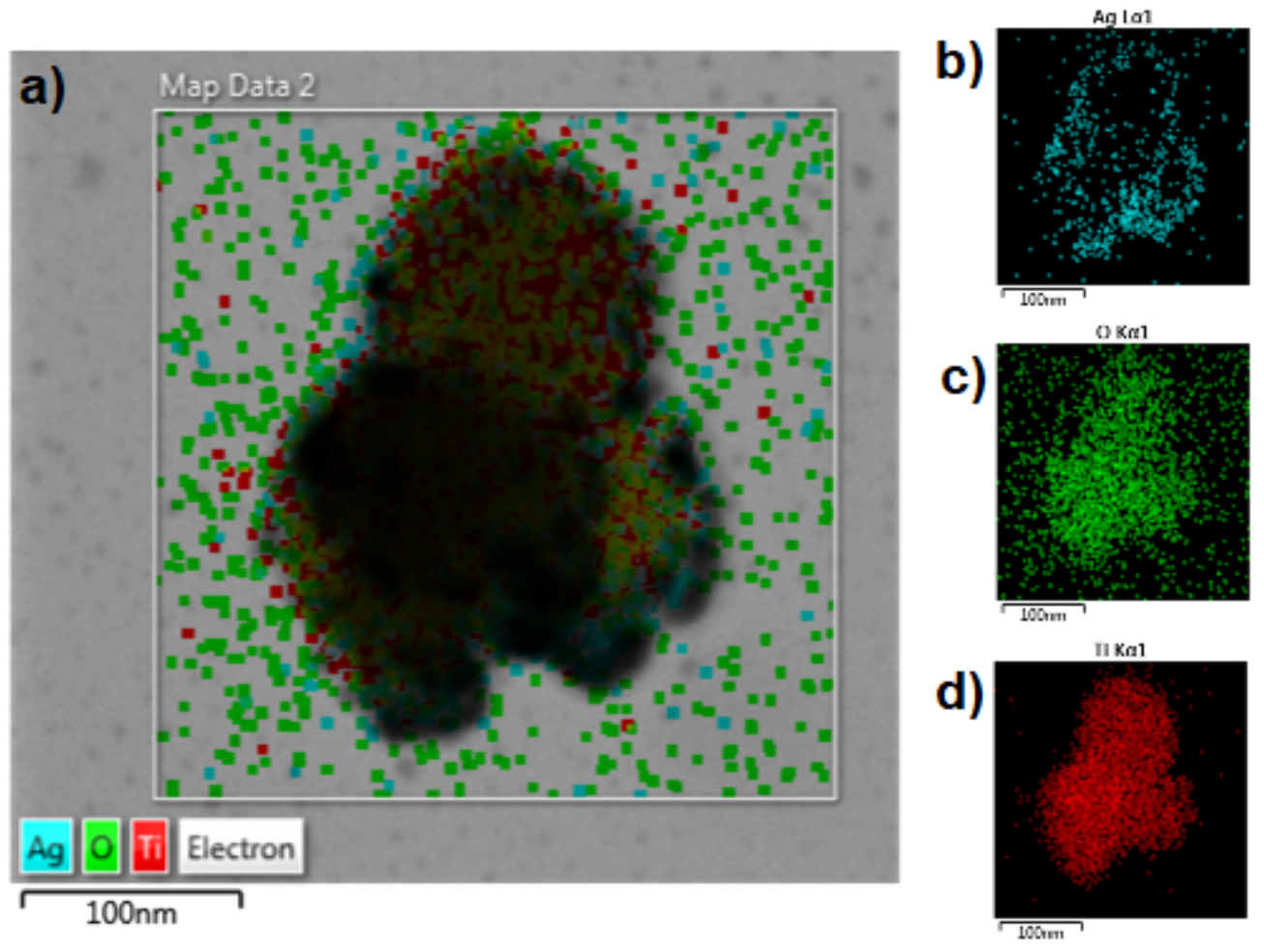

\section{Figure 14}

TEM/EDS analysis of the CCD experimental unit 1 of two factors: a) Ag/ TiO2 morphology, b) Ag distribution, c) 02 distribution, and d) Ti distribution

\section{Supplementary Files}

This is a list of supplementary files associated with this preprint. Click to download.

- GraphicalAbstract.tif 